\title{
Defense Science Board Task Force on \\ Vertical Integration and Supplier Decisions
}

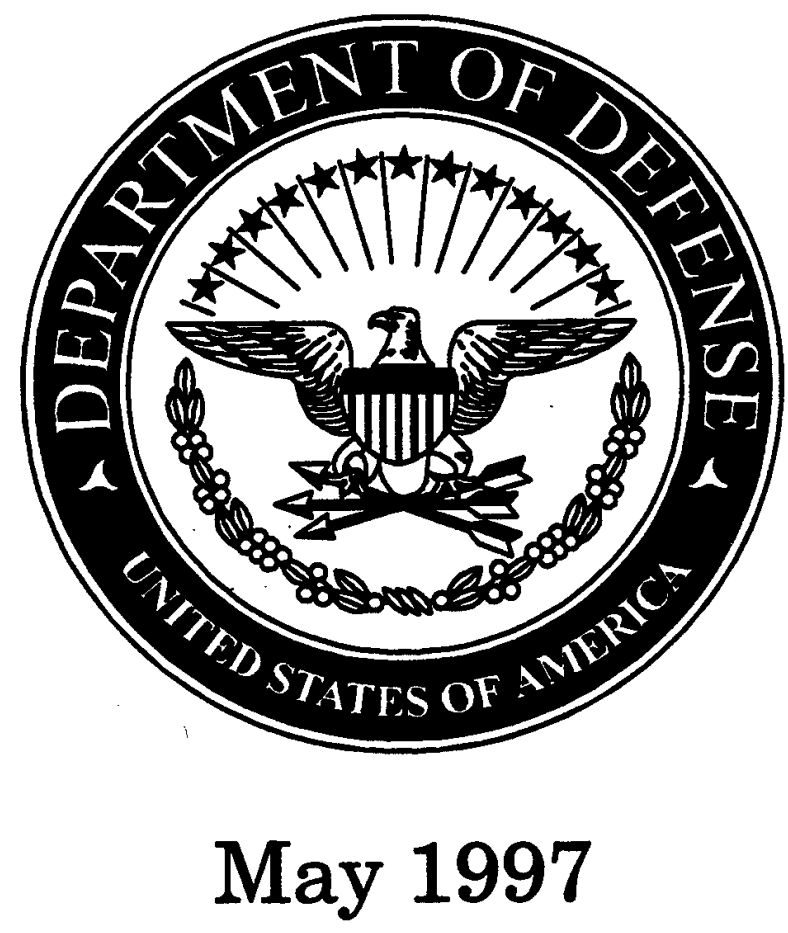

Office of the Secretary of Defense Washington D. C. 20301-3140

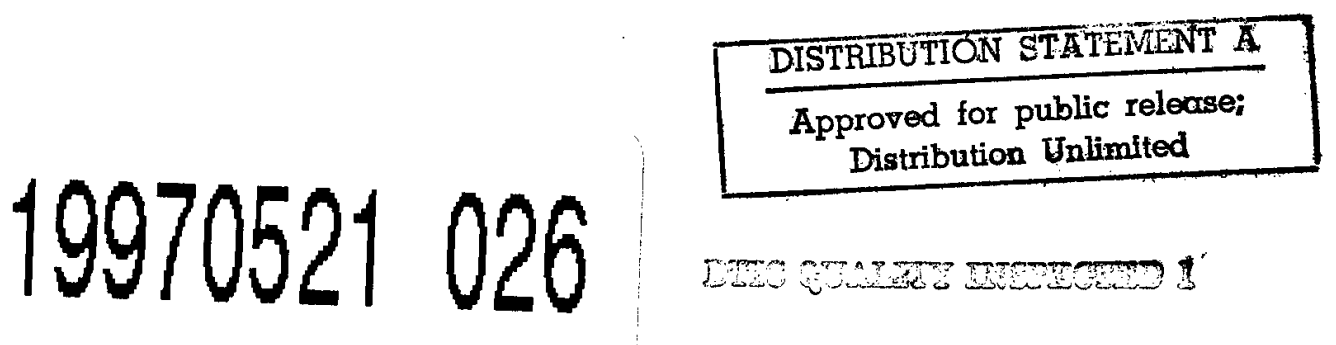


This report is a product of the Defense Science Board (DSB). The DSB is a Federal Advisory Committee established to provide independent advice to the Secretary of Defense. Statements, opinions, conclusions, and recommendations in this report do not necessarily represent the official position of the Department of Defense.

This volume is UNCLASSIFIED. 
Public reporting burden for this collection of information is estimated to average 1 hour per response, including the time for reviewing instructions, searching existing data sources, gathering and maintaining the data needed, and completing and reviewing the collection of information. Send comments regarding this burden estimate or any other aspect of this collection of information, including suggestions for reducing this burden, to Washington Headquarts Services, Dirm Davis Highway, Suite 1204, Artington, VA 22202-4302, and to the Office of Management and Budget, Paperwork Reduction Project (0704-0188), Washington, DC 20503.

\begin{tabular}{|c|c|c|}
\hline 1. AGENCY USE ONLY (Leave blank) & \begin{tabular}{|c|c|} 
2. REPORT DATE & 3. R \\
May 1997 & \\
\end{tabular} & $\begin{array}{l}\text { D DATES COVERED } \\
\text { Final }\end{array}$ \\
\hline $\begin{array}{l}\text { 4. TITLE AND SUBTITLE } \\
\text { Vertical Integration and Supplier De }\end{array}$ & isions & $\begin{array}{l}\text { 5. FUNDING NUMBERS } \\
\text { N/A }\end{array}$ \\
\hline $\begin{array}{l}\text { 6. AUTHOR(S) } \\
\text { Defense Science Board Summer Stu }\end{array}$ & & \\
\hline $\begin{array}{l}\text { 7. PERFORMING ORGANIZATION NA } \\
\text { Defense Science Board } \\
3140 \text { Defense Pentagon } \\
\text { Washington, DC } 20301-3140\end{array}$ & E(S) AND ADDRESS(ES) & $\begin{array}{l}\text { 8. PERFORMING ORGANIZATION } \\
\text { REPORT NUMBER } \\
\text { N/A }\end{array}$ \\
\hline $\begin{array}{l}\text { 9. SPONSORING/MONITORING AGEN } \\
\text { Office of the Under Secretary of De } \\
\text { 3015 Defense Pentagon } \\
\text { Washington, DC } 20301-3015\end{array}$ & $\begin{array}{l}\text { Y NAME(S) AND ADDRESS(ES) } \\
\text { nse (Acquisition and Technology) }\end{array}$ & $\begin{array}{l}\text { 10. SPONSORING/MONITORING } \\
\text { AGENCY REPORT NUMBER } \\
\text { N/A }\end{array}$ \\
\hline
\end{tabular}

\section{SUPPLEMENTARY NOTES}

Statement A: Approved for Public Release: distribution unlimited

\section{ABSTRACT (Maximum 200 words)}

This report provides findings and recommendations on the Department of Defense's needs to determine whether vertical integration has increased in the defense industry, to understand its potential effects on defense products, and to identify whether the Department should take any action.

\section{SUBJECT TERMS}

Techelot $\mathrm{F}$

DEFENSE INDISTRY; VERTICAL INTEGRATUUV: INDASTRY OF REPORT

Unclassified

\section{OF THIS PAGE}

Unclassified
15. NUMBER OF PAGES

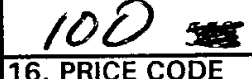

16. PRICE CODE
COASCLIDATION N/A

20. LIMITATION OF ABSTRAC OF ABSTRACT

Unclassified 


\section{MEMORANDUM FOR THE UNDER SECRETARY OF DEFENSE (ACQUISITION AND TECHNOLOGY)}

SUBJECT: Report of the Defense Science Board (DSB) Task Force on Vertical Integration and Supplier Decisions

I am pleased to forward the Final Report of the Task Force on Vertical Integration and Supplier Decisions. This Report responds to the Department's need to determine whether vertical integration has increased in the defense industry, to understand its potential effects on defense products, and to identify whether the Department should take any actions.

The Task Force was chaired by Bill Howard. They examined the defense industry consolidation to date and found that major defense firms have increased vertical integration in some product areas. This increased vertical integration appears to be a secondary effect, rather than a goal, of firms' consolidation actions.

The Task Force determined that defense industry vertical integration is not posing a systemic problem today. While a few defense mergers and acquisitions have posed vertical concerns, these have been identified and remedied in the antitrust process. The Task Force was presented with little evidence of problems resulting from vertical integration in current programs or among firms in ongoing operations with each other. However, the Task Force found that vertical integration poses potential concerns over time. The industry is more concentrated and there are few new program opportunities; this may create a static business environment that fosters new incentives for firms to leverage their vertical capabilities for potential harm.

The Task Force concluded that DoD's process to review mergers and acquisitions is effectively addressing vertical concerns. However, they concluded the Department needs to improve its ongoing acquisition processes so that DoD managers can identify and address emerging vertical integration concerns.

The Task Force has proposed a set of clear recommendations that can be quickly implemented, without adding bureaucracy or new reporting demands. I strongly support their findings and recommendations, and propose that you review the Chairman's letter and Report.

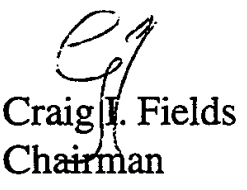




\section{OFFICE OF THE SECRETARY OF DEFENSE \\ 3140 DEFENSE PENTAGON \\ WASHINGTON, DC 20301.3140}

ENSE SCIENCE

BOARD

\section{MEMORANDUM FOR THE CHAIRMAN, DEFENSE SCIENCE BOARD}

\section{SUBJECT: Report of the Defense Science Board (DSB) Task Force on Vertical Integration and Supplier Decisions}

Attached is the final report of the Task Force. We were asked to determine whether vertical integration has increased in the defense industry, its potential effects on defense products, and whether DoD's acquisition reforms may mitigate any harmful effects.

The Task Force found that, as a result of consolidation, several major defense firms have increased vertical capabilities. Firms that provide integrated defense systems have gained a number of business units that typically supply subsystems of components. It does not appear that vertical integration was a primary goal of the consolidation, but a collateral effect. While some large defense transactions are still pending, the course and extent of future consolidation is unclear, and as such the Task Force could not predict its effects on vertical integration.

We were presented with little evidence that vertical integration is creating systemic problems for DoD products today. DoD program managers of existing programs reported that their prime contractors are not switching from committed suppliers to newly acquired internal "vertical" sources. This may in part be because the cost and risk of switching suppliers in programs already underway mitigates such tendencies.

However, we believe vertical integration poses potential future concerns to DoD. The industry is more concentrated, and many of the industry mergers and acquisitions are very recent. All of the effects of these new industry conditions cannot yet be assessed, but they could promote new incentives for firms to leverage their vertical capabilities over time in ways that could be harmful to defense product cost, quality, or performance.

We examined how DoD's current processes, including some acquisition reform initiatives, address vertical integration. Regarding the antitrust process, the Task Force found the Department has been working very effectively with the antitrust agencies to identify and remedy vertical concerns raised by the proposed transactions. The Department has adopted many measures proposed by the 1994 DSB report on "Antitrust Aspects of Defense Industry Consolidation," In so doing, the Department has made substantial improvements in its process for reviewing mergers and acquisitions, and in its ability to coordinate smoothly with the antitrust agencies. 
In acquisition programs, the Task Force believes, DoD managers may have difficulty recognizing emerging problems posed by vertical integration. The Department has significantly changed its buying practices since 1993, and is asking prime contractors to bid more comprehensive packages of mission and logistics requirements. Program managers are removing themselves from detailed oversight of their prime's day-to-day operations, and have limited interaction with suppliers below the prime. These changes are altering the dynamics among DoD managers, prime contractors, and suppliers.

Overall, the Task Force concludes that the Department is not well postured in its ongoing acquisition management processes to recognize or address problems emerging as a result of vertical integration. We are making five recommendations intended to strengthen DoD's ability to identify and address vertical integration:

1. Expand the Department's monitoring of vertical supply relationships for selected, important defense products and technologies.

2. Focus DoD acquisition and technology strategies and investments to support competition and innovation.

3. During antitrust reviews, continue to scrutinize carefully the potential harms from vertical integration.

4. Strengthen business- and industry-related skills of DoD's acquisition personnel.

5. Develop measures that help DoD managers to recognize areas of potential vertical integration concern and trigger more detailed investigation

In accordance with Dr. Kaminski's request, we also propose some initial measures the Department might use to indicate product areas warranting investigation due to potential vertical integration concerns. We believe that by taking these modest steps, DoD managers and decision makers will have the insight they need to assess vertical integration concerns and take positive action.

This Report represents the consensus of all members of the Task Force. I want to recognize and thank each of them for their participation and dedication to addressing this very complex subject. Their hard work and expertise is reflected in the attached Report, which I believe provides the Department with a thoughtful approach for addressing a very important matter.

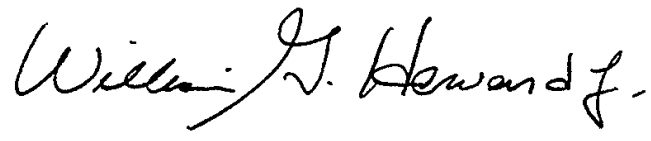

William G. Howard

Task Force Chair 


\section{TABLE OF CONTENTS}

TABLES

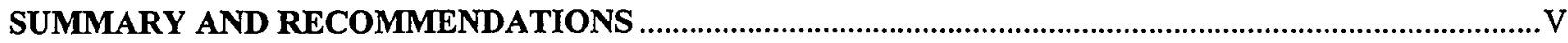

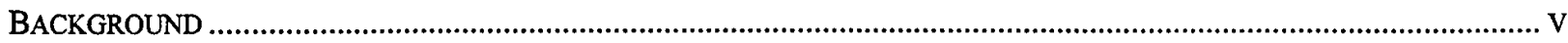

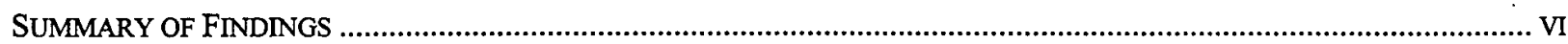

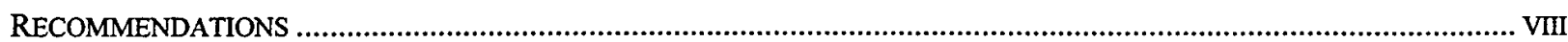

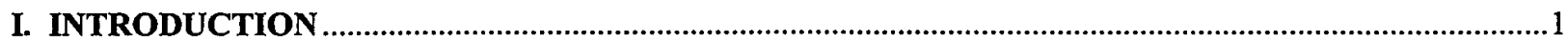

A. FORMATION OF THE TASK FORCE

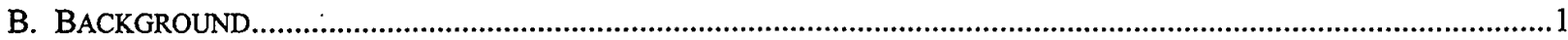

C. SHOULD DOD BE CONCERNED ABOUT VERTICAL INTEGRATION?

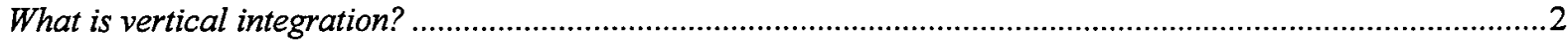

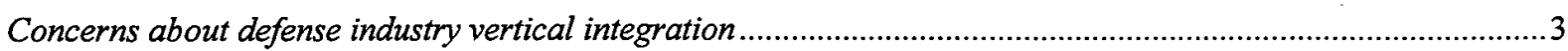

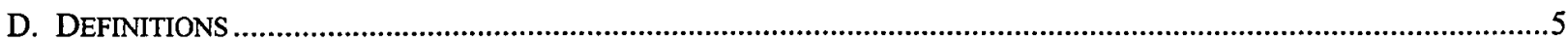

II. CONSOLIDATION HAS INCREASED VERTICAL CAPABILITIES IN SOME DEFENSE FIRMS.......7

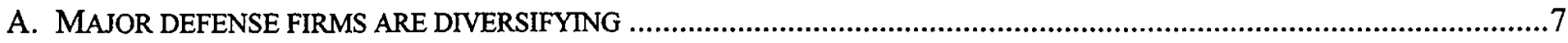

B. FURTHER CONSOLIDATION EFFECTS ON VERTICAL INTEGRATION ARE UNCLEAR ...................................................11

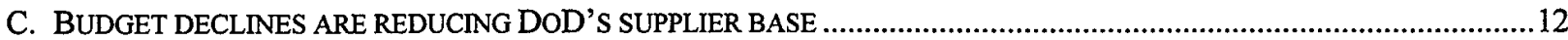

III. VERTICAL INTEGRATION DOES NOT APPEAR TO BE A SYSTEMIC PROBLEM TODAY BUT

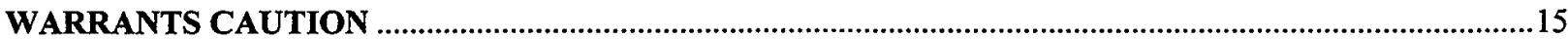

A. SOME DEFENSE MERGERS AND ACQUISITIONS HAVE POSED VERTICAL INTEGRATION CONCERNS ...........................15

B. THE TASK FORCE FOUND LIMITED EVIDENCE OF PROBLEMS ...........................................................................

C. IN EXISTING PROGRAMS, THE COST OF SWITCHING SUPPLIERS MITIGATES VERTICAL INTEGRATION TENDENCIES ...18

D. VERTICAL INTEGRATION POSES POTENTIAL FUTURE CONCERNS TO DOD …........................................................19

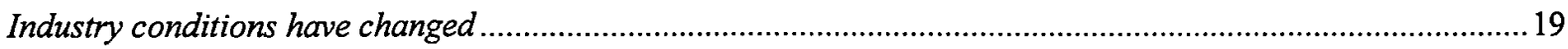

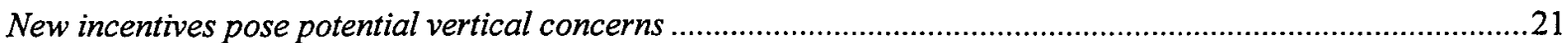

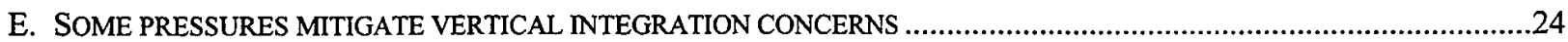

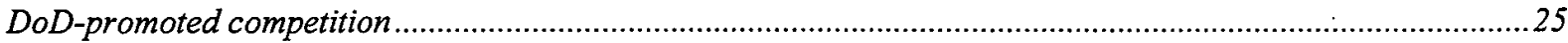

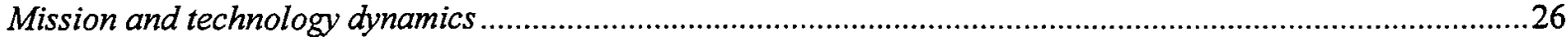

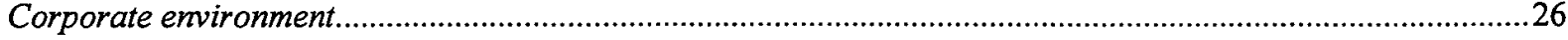

DoD acquisition reforms to encourage more suppliers .....................................................................................27 
A. DOD'S PROCESS TO REVIEW MERGERS AND ACQUISITIONS IS APPROPRIATE FOR VERTICAL ISSUES AND IS WORKING WELL

Antitrust agency and DoD reviews are complementary

Antitrust reviews of defense industry are successfully addressing some less traditional vertical concerns...........31

B. DOD'S ACQUISITION PROCESSES PROVIDE LITTLE VISIBILITY INTO SUPPLIER PRODUCTS AND TECHNOLOGIES ........33

DoD acquisition managers have less interaction with suppliers. .33

Individual DoD acquisition managers do not have industry-wide visibility... 35

DoD Headquarters staffs create policy and solve problems - they do not monitor industry... .37

Conclusion.

APPENDICES

APPENDIX B. TASK FORCE CHARTER, MEMBERSHIP, MEETINGS, AND BRIEFING TOPICS ......B-1

CHARTER

MEMBERSHIP ROSTER

MEETING DATES AND BRIEFINGS

APPENDIX C. GLOSSARY

FTC/DOJ ANTITRUST REVIEW PROCESS

MERGERS AND ACQUISITIONS: 1994-PRESENT.

APPENDIX E. PRIME CONTRACTORS" "MAKE" VALUE IN EXISTING DOD PROGRAMS

SYSTEM UPGRADE PROGRAM: F-18 C/D TO F-18 E/F

ONGOING SYSTEM DEVELOPMENT PROGRAM: F-22

NEW SYSTEM DEVELOPMENT PROGRAM: JofNT STRIKe Fighter

APPENDIX F. SOME CHANGING DOD ACQUISITION PRACTICES.

SELECTING SUPPLIERS

PACKAGING NEW DOD SYSTEM BUYS F-2

DECREASED DOD MANNING. F-5 


\section{TABLES}

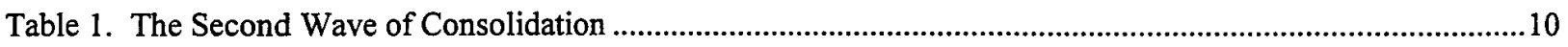

Table 2. Firms with Top Two-Thirds of Defense Product Sales ...........................................................................20

Table 3. Pressures Mitigating and Encouraging Harmful Effects from Vertical Integration ..................................24

Table 4. Programs Reviewed for Supplier Oversight and Vertical Integration .......................................................35

Table 5. Appropriate Tools To Address Vertical Concerns Vary by Product Phase or Maturity ........................... D-2

Table 6. Antitrust Review Process Flow and Associated Time Periods ................................................................. D-2

Table 7. Notable Merger and Acquisition Cases: March 1994-March 1997 ....................................................... D-3

Table 8. Vertical Concerns and Remedies in Defense Mergers and Acquisitions............................................... D-5

Table 9. Average Defense Prime "Make" Values, 1991 …................................................................................ E-1

Table 10. F-18 Prime/Partner Make/Total Value .................................................................................................

Table 11. F-22 Prime "Make"/Total Value ......................................................................................................... E-4

Table 12. F-22 Prime Contractors and Major Subcontractors ................................................................................... E-5

Table 13. Joint Strike Fighter (JSF) Major Contracts...................................................................................... E-6

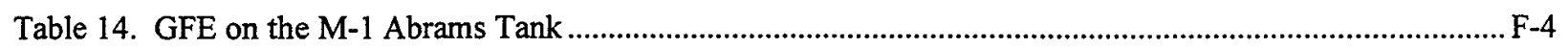




\section{SUMMARY AND RECOMMENDATIONS}

\section{Background}

The sharp decline in spending by the Department of Defense (DoD) since 1985 has resulted in a dramatic consolidation in the defense industry. The consolidation has involved large and small firms in nearly every primary defense product market. Overall, the Department views the consolidation as a natural and necessary industry response to the budget decline. The consolidation is reducing excess capacity which, in turn, reduces costs for defense programs. ${ }^{1}$ Since 1994, when many larger mergers and acquisitions began, the Department of Defense has increased its role in antitrust reviews. A 1994 DSB Task Force report, Antitrust Aspects of Defense Industry Consolidation, advised the Department of Defense to define a process to determine its views on a given transaction and to better communicate with the antitrust agencies. The Department has taken many steps recommended by the 1994 Task Force report. Consequently, the two antitrust agencies - the Federal Trade Commission and the Department of Justice-and industry indicate there have been significant improvements in DoD involvement in the antitrust process.

Some mergers and acquisitions since 1994 have raised issues of increased vertical integration in defense firms, a matter not addressed in the 1994 Task Force report. A vertically integrated firm is one that owns the capability to internally supply some of the subsystems or components it needs for its other products. The fact that firms are vertically integrated does not necessarily mean they will act in a way that causes harm to other firms or to the Department of Defense. In addition, a firm does not have to be vertically integrated to act in an exclusionary manner. ${ }^{2}$ However, vertical integration enables several potential behaviors that may negatively affect defense product cost, quality and performance.

The Department of Defense asked this Task Force on Vertical Integration and Supplier Decisions to determine if vertical integration has increased, if it poses concerns for defense products, and if so, how the Department might recognize and address them. This report addresses the industry that provides integrated defense systems - for example, tanks, aircraft,

1 Because the Department of Defense pays for appropriate contractors' overhead costs as a part of its contracts, DoD contract costs are reduced when their contractors' overhead rates are reduced.

2 For example, DoD product competition could be harmed if a non-vertically integrated firm denies other firms access to a technology that is critical to building their products. 
ships, satellites-and the subsystems and components needed to build them. It is not intended to address common commercial commodities or services (for example, petroleum, telephone or construction services, etc.) procured by the Department of Defense, or vertical integration in the firms that provide these commercial commodities or services.

\section{Summary of Findings}

\section{Consolidation has increased vertical capabilities in some defense firms}

This Task Force found that, as a result of the consolidation, several major defense firms have increased vertical capabilities. Specifically, major firms that typically provide integrated defense systems have gained a number of business units that are "vertical," that is, business units that typically supply subsystems or components. ${ }^{3}$

Vertical integration does not appear to be a primary goal of the consolidation but a collateral effect of firms' goals to buy good businesses with backlog orders and to increase diversification for future sales. Some analysts project a follow-on "portfolio-shaping" consolidation phase in which firms will sell or trade some business units to focus on core business capabilities. The Task Force could not project the extent or effects of a possible portfolio shaping phase on newly acquired vertical capabilities. In the current defense business climate, firms may want to hold on to vertical capabilities that are important or discriminating for defense system performance.

Vertical integration does not appear to be a systemic problem today but warrants caution.

The Task Force found little evidence that vertical integration is creating systemic problems for DoD products today. A few vertical concerns have been identified and remedied in defense merger and acquisition reviews. In existing DoD acquisition programs, firms are less likely to use newly acquired vertical businesses to replace current suppliers because of the cost and risk of switching suppliers.

However, the Task Force believes vertical integration poses future concern to DoD. Many industry mergers and acquisitions are very recent, and all of their effects cannot yet be assessed. The concentrated defense industry and few new DoD program opportunities create

3 The Task Force is defining this increase in firms' subtier or vendor capabilities as increased vertical integration. We based this on examining the breadth and mix of business units that have been combined under larger corporate entities as a result of consolidation. The Task Force could not explicitly measure the extent of increased vertical integration. Industry analysts and antitrust agencies reported that they neither measure industry-wide vertical integration nor have a mechanism to do so. 
a potentially static business environment. These altered conditions in the industry could change incentives for firms to employ vertical integration to their advantage. In so doing, firms might disadvantage other firms; this would potentially affect defense product cost, quality, or performance. Some market pressures-including active competition at the prime level, changes in missions and technologies, and internal corporate dynamics-create incentives that mitigate against firms using internal capabilities preferentially, and over time, might motivate firms to shed vertical business units. The Department's acquisition reforms to encourage use of commercial products and open systems architectures in defense systems may also contribute to fostering a competitive defense market. The Task Force concluded, however, that these mitigating forces alone may not be adequate safeguards to protect the Department's interests for a competitive, innovative supplier base in the future.

\section{How the Department of Defense deals with vertical integration}

Because vertical integration may pose concerns in the future, the Task Force considered methods the Department might use to improve its ability to recognize and address any such concerns. The Department of Defense affects vertical integration in two ways: in its participation in antitrust reviews of proposed industry mergers and acquisitions, and in its ongoing management of $\mathrm{DoD}$ acquisition programs.

- Regarding the antitrust review process, the Task Force found the Department of Defense has been working very effectively with the antitrust agencies to identify and remedy vertical concerns raised by proposed transactions. The Task Force has no recommendations for improvement in the Department's antitrust process, but we propose some considerations. The Task Force has no recommendations for change in DoD's review process, but we propose a list of considerations DoD should be (and appears to be) addressing in its reviews of mergers and acquisitions with potential vertical effects (Recommendation 3).

- In acquisition programs, the Task Force believes DoD managers may have difficulty recognizing emerging problems posed by vertical integration. The Department has significantly changed its buying practices since 1993. It is asking prime contractors to bid to more comprehensive packages of mission and logistics requirements, and program managers are removing themselves from detailed oversight of their prime contractor's daily operations. These reforms are changing the dynamics between DoD managers, defense primes, and suppliers. DoD program personnel have increasingly less interaction with suppliers or products below the prime level. Also, they are often unable to see the effects of their individual program decisions on the broader industrial capabilities. 


\section{Recommendations}

The Department of Defense is not well-postured in its acquisition programs to recognize or address problems emerging as a result of vertical integration. The Task Force offers five recommendations to strengthen the Department's knowledge of the effects of vertical integration in the defense industry, and its ability to ameliorate potential problems posed by vertical integration.

Recommendation 1. Expand the Department's monitoring of vertical supply relationships for selected important defense products and technologies.

Recommendation 2. Focus DoD acquisition and technology strategies and investments to support competition and innovation.

Recommendation 3. During antitrust reviews, continue to scrutinize carefully the potential harms from vertical integration.

Recommendation 4. Strengthen business- and industry-related skills of the Department's acquisition personnel.

Recommendation 5. Develop measures that help DoD managers to recognize areas of potential vertical integration concern and trigger more detailed investigation.

\section{Recommendation 1. Expand the Department's monitoring of vertical supply relationships for selected important defense products and technologies.}

The Department of Defense should increase its monitoring of vertical supply
relationships for selected important products and technologies on an ongoing
basis. The appropriate Office of the Secretary of Defense organization needs
to track key supply product areas that affect multiple programs and matters
that individual program managers may not be addressing. Individual program
managers need to address potential problems arising in their programs.

The Department of Defense may not be able to discern whether, or when, vertical integration is causing a problem, in part because it lacks visibility into important supplier product areas. With acquisition reform and reduced DoD manning, the Department's acquisition program managers must increasingly limit their interaction to prime contractors and areas of high risk. 
DoD and Service headquarters level staffs typically provide policy and address industry problems; they do not gain ongoing insight to compensate for program managers' limited supplier visibility. The Department is delegating more responsibility to primes and is decreasing its visibility of firms below primes. In contrast, successful commercial firms are delegating more of the job but increasing their knowledge of their suppliers of important products to protect themselves. DoD acquisition managers must, and should, rely on their prime contractors to manage the suppliers for their programs. However, the Department has an important role to play with suppliers. It has goals and incentives different from prime contractors, and it needs to form its own views of the health of competition and innovation in important supplier markets.

DoD-wide visibility. The Under Secretary of Defense for Acquisition and Technology (USD(A\&T)) already provides industry-wide assessments and policy guidance through the Deputy Under Secretary for Industrial Affairs and Installations (DUSD(IA\&I)). Without creating new or additional bureaucracy, the current DUSD(IA\&I) role could be expanded to include active, systematic monitoring of key defense supply areas on a selective basis. The goal of this active approach is to identify concerns early, to use this insight in antitrust reviews, and to coordinate DoD acquisition and technology investments to offset concerns early-while there is still solution flexibility. The DUSD(IA\&I) should identify a limited number of important products and technology areas to monitor (for example, ten to twenty areas) that affect multiple programs. ${ }^{4}$ These areas must be dynamic-changing as the industry, technology, and DoD requirements change. IA\&I should identify these areas in consultation with industry and $\mathrm{DoD}$ acquisition program and technology managers, using the criteria identified later in this summary.

DoD executive-level visibility. The USD(A\&T) should build on an existing internal executive-level body with the Service Acquisition Executives, such as the Industrial Base Executive Committee (IBEC), to elevate attention to vertical integration. DUSD(IA\&I) can use this forum to promulgate supplier knowledge and awareness among DoD executives, and to elevate areas of potential concern to acquisition and technology decision makers. DUSD(IA\&I) should propose and gain the consensus of this executive group on its selected key product and technology areas. For the next two or three years, the DUSD(IA\&I) should

4 The Task Force believes the Department cannot and should not monitor every area, and proposes that it will be more effective if it focuses on a limited number of carefully selected areas. Suggesting ten to twenty areas is illustrative; the Department may need to select more or fewer than this. 
meet with this group twice a year to review these areas and agree on how to address any potential problems.

\section{Criteria to identify key areas}

- Products or technologies that are discriminators of leading-edge defense system capability and/or cost. Of special concern are discriminating products or technologies in industry sectors where the number of prime market competitors is, or may drop below three.

- Technologies that have received significant DoD funding (relative to the market size) or where firms are unlikely to invest in consequential new developments without winning additional DoD funding programs.

- Areas where there are (or are likely to be) few market suppliers or where suppliers address only specialized sub-markets, and where most (or the preeminent) suppliers are parts of vertically integrated firms.

- Areas identified as a potential concern in an earlier antitrust review or remedy.

DoD-wide measures. For its selected key product and technology areas, IA\&I should report on the following measures to the DoD executive group (such as the IBEC):

- The degree of competition for the area, and potential entrants.

- The health and performance of firms in the market area.

- The pace of technology change in firms and in the industry.

IA\&I should not collect additional data from defense firms for this purpose, where data already exists in the public domain, in DoD program offices, and/or in other DoD organizations. DoD program offices should provide data about their program prime and supplier sources and prime "make" value to the ODUSD(IA\&I). DUSD(IA\&I) can use this data to build metrics or trends to help program managers judge their programs. The IA\&I staff need skills similar to those of intelligence and investment analysts. They must be resourceful data collectors and be able to analyze objectively technical, business, and financial data on a diverse set of product areas.

5 Examples of key product and technology areas include high temperature and specialty materials (low observable materials, single/grown crystal metallics), diode-pumped lasers (for special applications), focal plane arrays, missile seekers, fire control systems, monolithic microwave integrated circuits, and large-scale composite structures. 
Program office visibility. Individual DoD program managers and program executive officers also need to increase their awareness of vertical integration in selected key products and technology areas. They can do this without adding burdensome oversight or new data collection. Generally, they should be alert when prime contractors favor in-house sources of supply over external suppliers who appear to have superior technology or quality. They should examine areas where it appears their primes are not buying from rival firms that are recognized as preeminent or historically best value suppliers in that area. This is to ascertain whether their prime is excluding the rival supplier by choice, or if that supplier has been made unavailable by its parent firm for anti-competitive reasons. DoD program managers and program executive officers should pay particular attention to vertical integration issues at two points:

- Before contract award for defense system developments, they should ask prime contractors to provide subcontractor, teaming, and "make or buy" plans (allowed by existing Federal Acquisition Regulation (FAR) provisions).

$\checkmark$ They should ask primes to describe how they are addressing key product and technology competition, and to identify proposed subcontractors for those areas (existing provisions of the FAR allow for this).

$\diamond$ They can use the prime's "make" content-the percentage of in-house product work or value-in key product or technology areas as a potential indicator of areas that merit further review. They should compare proposed prime "make" content in the program overall, and in major subsystem areas, with current and previous similar programs. Areas that appear very changed may warrant further examination (for example, compare capabilities of proposed vertically integrated sources with those of external suppliers).

- After the contract is awarded, the program office should monitor changes from buy to make over the life of the contract for key subsystems and components, and for changes over a selected dollar value. They should monitor how the prime contractor is partitioning the system design to understand how this may restrict supplier choices for these key subsystems or components.

Program offices should call on DUSD(IA\&I) for industry expertise in planning their programs and reviewing prime contractors' proposed "make or buy" decisions for key product areas. As a minimum, program offices should provide informational copies of data about their program prime and supplier sources and prime "make" value to the 
ODUSD(IA\&I). DUSD(IA\&I) can use this data to build metrics or trends to help program managers judge their programs.

If DoD managers identify real problems. If the Department's efforts to prevent a problem from arising do not fully succeed, individual program managers may face an immediate problem on their program. Current laws and policies provide the Department of Defense with many tools it can employ to address such problems. Appendix A outlines these tools (though the list is not exhaustive). Some of the tools are within the immediate control of an individual program manager; others may require executive-level implementation as they necessitate cross-Service or cross-DoD actions.

\section{Recommendation 2. Focus DoD acquisition and technology strategies and investments to support competition and innovation.}

The Department of Defense should revise its policy and practices to increase the focus on retaining competition and innovation in its acquisition and technology programs.

Defense industry conditions have changed, and DoD acquisition managers need to alter some of their approaches in acquisition and technology programs to ensure a future competitive and innovative supply product market. Actions that the Department takes to affect primelevel competition can also affect supply relationships. The Department of Defense should not wait until problems occur to act: Supply relationships in acquisition programs are often solidified early in the program and the Department's mitigation options diminish as programs progress.

DoD should require that the acquisition strategies of DoD program managers' explicitly:

- Assess the competitiveness of markets for selected and key product and technology areas relevant to the program.

- Consider how the Department is partitioning its overall buy (e.g., air and ground elements, logistics and production, etc.) and how that may affect the potential set of qualified bidders currently and in the future.

- Consider and propose alternatives that foster competition at both prime and key subtier product areas. Strategies should explicitly identify alternative products and/or technologies that represent potential strategic competition alternatives for the product 
being proposed or acquired. Additionally, the acquisition strategy might propose methods to permit additional entrants-such as allowing for a twelve- to eighteenmonth pre-developmental phase-so that potential suppliers can achieve competence to compete in areas requiring specialized development.

- Require an open system definition based on maximizing the number of potential suppliers for key systems areas.

The DUSD(IA\&I) staff should participate in reviewing program acquisition strategies to assure that DoD-wide industry knowledge and actions are shared.

DoD internal weapons system Overarching Integrated Product Teams (OIPTs) and IPTs should ensure that programs address competition and innovation for key products and technologies at critical new and upgrade program points, including weapons systems concept studies, milestone decisions, establishing acquisition strategies, and preliminary interactions with bidders in development phase programs.

Additionally, the Department should consider the effects of its research and development funding decisions on supplier competition, as they might inadvertently exacerbate vertical integration problems. The Department may need to fund alternative concepts and technical approaches as a way to stimulate competitive alternatives in key subsystem or component product or technology areas. To increase coordination among technology, acquisition programs, and industry, the DUSD(IA\&I) and the Office of the Secretary of Defense acquisition program oversight executives (e.g., Director, Tactical and Strategic Systems; DUSD (Space)) should participate in DoD's science and technology (S\&T) area plans and investment strategies in key supply product areas of concern.

Recommendation 3. During antitrust reviews, continue to scrutinize carefully the potential harms from vertical integration.

Antitrust reviews must continue to scrutinize carefully the important sub-tier capabilities involved in the transaction, and the potential for the parties to now have altered economic incentives.

The Task Force concluded that the antitrust review process has been effective in dealing with vertical integration issues to date. However, with few new programs, a static DoD budget, and increased industry concentration, the potential for future mergers and acquisitions to pose vertical concerns is increasing. 
During the antitrust review process, the Department of Defense should examine the parties' subtier capabilities to identify those that could significantly discriminate prime-level products, or those which, if access were denied, could disadvantage rivals. The Task Force has no recommendations for change in the Department's review process, but we propose a list of considerations that the Department should be, and appears to be already, addressing in its reviews of vertical cases:

Considerations for reviews of mergers and acquisitions with vertical issues

- Would the combined firms be postured to cause harm to other defense firms as a result of vertical integration? What are the likely economic incentives for them to do so?

$\checkmark$ Do the merging parties together represent the preeminent technical capability in important or discriminating product or technology areas?

$\diamond$ Can they prevent other firms from entering the market by enforcing patent rights or denying them access in other ways?

- Are there key or discriminating subtier product areas where either party could supply the other party that have been the focus of significant DoD S\&T funding (significant relative to the market size)? If the proposed acquisition or merger involves an important technology that has been developed with U.S. government funding, do mechanisms exist to ensure that it will be available to other companies?

- How much time and investment is required for other firms to either remain in the business or to become serious competitors to the vertically integrated firms subtier business? Is there sufficient return on investment to entice potential competitors to enter the business?

- Have the merging firms preferred internal supply sources in the past?

- Are firms that now depend on access to important or discriminating product or technology areas expressing concern about the effects of the merger and/or acquisition? 
Recommendation 4. Strengthen business- and industry-related skills of the Department's acquisition personnel.

The Department of Defense should expand curricula at the defense acquisition
schools (Defense Systems Management College, Industrial College of the
Armed Forces, etc.) to include additional coverage and depth of industrial
knowledge and analysis techniques. The acquisition career field education and
training program should incorporate rotational assignments (similar to the
Presidents' Executive Exchange) in industrial and financial firms where
students can gain strategic and financial experience in an operating business
environment. Additionally, the Department should increase its emphasis on
relevant business- and industry-related education, training, and experience
credentials in hiring and assigning acquisition personnel.

DoD acquisition managers make decisions and take actions that have profound effects on the industry. The Department of Defense has reformed its acquisition practices to change its relationship with industry, but it has done too little to reform DoD managers' industry-related skills. The current acquisition practices and industry environment require DoD managers to have improved knowledge and savvy of their relevant product markets, industrial capabilities, and firms' economic incentives. Successful firms increasingly find that smart buying personnel are critical to their market competitiveness and are filling these jobs with highly skilled people. The current education, training, and experience requirements for its acquisition positions emphasize understanding of the Department's unique acquisition regulations and practices. Understanding of how industry works is a peripheral credential.

Recommendation 5. Develop measures that help DoD managers to recognize areas of potential vertical integration concern and trigger more detailed investigation.

The Department of Defense should develop, based on experience, a portfolio of indicators that point to possible competitive concerns in key product areas. Several mechanisms already exist that serve as a start to this decision toolbox.

The Department of Defense needs a set of elementary measures or indicators of potential problems that may be emerging due to vertical integration. Conditions in specific product or technology areas differ substantially, and a universal set of trigger indicators is not feasible 
or desirable. However, using measures could help DoD acquisition managers and decision makers recognize and target areas for further investigation, without instituting universal supplier monitoring.

This Task Force proposes the following indicators. The data to create these indicators generally exist inside the $\mathrm{DoD}$, but much of it has not been centrally collected or reviewed. DUSD(IA\&I) staff should investigate the available data to develop these measures and test them by applying them in analyses. Based on experience, the DoD can revise, refine, or add to these indicators.

Competitors declining below three. If there are only one or two prime-level suppliers remaining for a defense product market area, or if a proposed merger or acquisition would create this condition, the Department should consider increasing its scrutiny of vertical integration in both the proposed transaction and in the Department's relevant product acquisitions. (If prime-level competition is too limited, it may create incentives for make/buy decisions that are not wholly "best value.") Similarly, the Department should increase its scrutiny if there are only two viable suppliers for important or discriminating technology or product areas, and one or both of these competitors are part of a vertically integrated firm; or if a merger or acquisition would create this condition.

Prime "make" percentage. In a weapons system program development or upgrade proposal, if a prime contractor proposes a "make" (internal value as a percentage of total value) in important or discriminating technology areas that is significantly higher than those prime "make" values seen in earlier, similar systems, the program office should investigate the cause of the shift towards in-house work. During antitrust reviews, the Department of Defense should examine the effects of the proposed merger or acquisition on firms" "make" percentage on existing major DoD programs. If the proposed transaction causes the "make" value of the combined company to significantly increase over that of the individual parties prior to the transaction, the Department should look closely at the effects of the transaction.

DoD investment in discriminating technology. Technology areas in which the Department of Defense has focused sizable funding (relative to the market) for research, development, and/or demonstration are often discriminating or important for defense systems performance. These DoD investments indicate areas of important new advancements and product applications where there may be few competitive suppliers. If firms were to deny other firms access to these technologies or products, they may be able to prevent the other firms from performing in certain markets. During antitrust reviews, the Department should scrutinize the growth of competitors' capabilities in these areas, of the potential concentration of these 
capabilities due to the transaction, and of the economic incentives of the acquiring firms. The Department should also consider these selected areas for its on-going monitoring (Recommendation One). 


\section{INTRODUCTION}

\section{A. Formation of the Task Force}

On May 23, 1996, the Under Secretary of Defense for Acquisition and Technology chartered this Task Force on Vertical Integration and Supplier Decisions. He asked the Task Force to "examine the effects of defense industry vertical integration and supplier decisions and make recommendations on what, if any, revisions to Department of Defense (DoD) policy, practice, or investment strategies are required to deal with these issues." He asked the Task Force to focus on the effects of vertical integration on defense product competition and innovation, to provide measures of the extent of defense vertical integration, and to suggest indicators the Department of Defense might use to identify emerging problems. Appendix B of this document sets forth the Terms of Reference. ${ }^{6}$

The Task Force comprised representatives of government, defense industry, academia, and legal and industry consultants. Defense industry representatives came both from large prime contractors with the Department of Defense and from firms that frequently provide products or services at the supplier level. Government advisors included representatives of the two antitrust agencies, the Department of Justice (DOJ) and the Federal Trade Commission (FTC). Appendix B provides a list of Task Force members.

Between September 1996 and January 1997, the Task Force conducted ten days of meetings at which it heard a wide range of views relative to the Task Force's assignment. Appendix B also includes a list of presentations made to the Task Force.

\section{B. Background}

The sharp decline in DoD spending since 1985 has resulted in a dramatic consolidation in the defense industry. In 1993 a Defense Science Board Task Force on Antitrust Aspects of Defense Industry Consolidation was chartered to provide advice "...concerning (1) appropriate criteria for determining the Department's views on a given transaction, (2) the

6 It is not the charter of this Task Force to assess endangered industrial capabilities. DoD has a policy (DoD Directive 5000.60, Defense Industrial Capabilities Assessments) and an analysis process (DoD Handbook $5000.60)$ to address critical industrial capabilities that may be "endangered" by a firm deciding to exit a defense product market, enter bankruptcy, etc. 
data required to do so, (3) the analytical capabilities required to do so, and (4) appropriate means for communicating with the enforcement agencies."

Publishing its report in April 1994, the Task Force noted that in many respects "competition among firms in the defense industry is significantly different than competition among firms in other sectors of the economy." Recognizing the Department of Defense has an important stake in defense industry consolidations that may raise competitive and national security issues, the Task Force report recommended increased constructive cooperation between the Department of Defense and the two antitrust agencies in merger and acquisition analysis.

Since that report was issued, the consolidation of the defense industry has continued. The Department of Defense has taken many steps recommended by the 1994 Task Force, and the antitrust agencies and industry indicate that there has been significant improvements in Department's involvement in the antitrust process.

Since the publication of the 1994 Task Force Report, some mergers and acquisitions that have occurred have raised issues of increased vertical integration in defense firms. While the 1994 Task Force Report addressed competition policy concerns in defense industry mergers, it did so only in the context of mergers between horizontal competitors; it did not address vertical integration. Therefore, the current Task Force was formed to address potential issues associated with vertical integration.

\section{Should DoD be concerned about vertical integration?}

\section{WHAT IS VERTICAL INTEGRATION?}

Definitions of vertical integration vary. Economists define vertically integrated firms as those that either do satisfy, or are able to satisfy, some or all of the inputs for their products or services internally (that is, from within the firm). To illustrate this concept, the defense industry may be thought of as consisting of vertical "tiers" of product and service suppliers: defense system integrators, subsystem and component suppliers. Companies in lower tiers provide elements for inclusion in higher-tier firms' products. In the defense industry context, a vertically integrated firm is one that can supply elements for its products in one tier from another tier internal to the firm. For example, a defense aircraft manufacturer may purchase

7 Defense Science Board, "Executive Summary," Report of the Defense Science Board Task Force Report on Antitrust Aspects of Defense Industry Consolidation, Washington, DC, AD-A278 619, April 1994. The report also noted that DoD's acquisition oversight (cost and other controls) is "an imperfect substitute for competition" (based on court precedent, discussed on page 28 of the 1994 report). 
another firm that has various capabilities, including a division that supplied aircraft avionics to third parties. The aircraft manufacturer is now able to produce its own avionics subsystems without going to outside suppliers.

For purposes of this report, firms that are able to produce some of the subsystems or components used in the products they sell to their customer are considered "vertically integrated."

\section{CONCERNS ABOUt DefENSE INDUSTRY VeRTiCAL INTEgRATION}

A vertically integrated firm will not necessarily act in a way that causes concern to the Department of Defense. Likewise, firms can employ business practices that exclude or harm other firms regardless of their internal structure. However, vertical integration does enable several potential practices that may be of concern to the Department of Defense as they could lead to defense products that are lower in performance, more costly, and of poorer quality. Even if it is not in the company's interest at the time of mergers and acquisitions to engage in harmful practices, future business conditions, new generations of company leaders, or changes in the economic incentives of the company can result in actions potentially harmful to competitiveness in the defense supplier base. The potential concerns about vertical integration include the following:

\section{Preferring internal over external suppliers}

Gaining new internal sources of supply may cause a parent firm to favor the internal source over external suppliers, even if external suppliers are superior. This can not only weaken supplier-level competition but result in inferior defense products. In fields as specialized as some defense products, if external suppliers cannot sell to a prime who favors internal sources, there may be few other buyers for the external suppliers' products. This may force competent suppliers to leave the field.

\section{Increasing barriers to market entry}

Vertically integrated firms who refuse to supply their competitors, or choose to supply them on undesirable terms, can raise barriers to the market entry of their competitors. If after a merger the new owner hinders or "forecloses" a competitor from continued supply of critical elements, the competitor may be unable to continue in business or to compete effectively. If other suppliers of critical elements are not available or are inferior, the competitor may have to develop an internal source of supply. Since the skill and investment required to succeed as a supplier may be very different from that of making the finished product, the cost of entry 
can be so high as to jeopardize the competitor's ability to succeed. Short of foreclosure, competitors may find themselves receiving less favorable prices, a less advanced product, or less advantageous terms from the supplier than before the acquisition.

Example: In the merger between Lockheed and Martin Marietta; the FTC was concerned about Lockheed's vertical integration into the manufacture and sale of both military aircraft and LANTIRN, a navigation and targeting system supplied by Martin Marietta that is a critical component of certain military aircraft. After the merger, Lockheed would be in a position to modify and upgrade LANTIRN in ways that could discriminate against its aircraft competitors, thereby raising the costs or reducing the performance of those competitors' aircraft. The FTC therefore ordered Lockheed not to make changes to LANTIRN that discriminate against other aircraft firms unless necessary to meet foreign competition, to compete with other night vision products, or as approved by the Secretary of Defense.

Alternatively, exclusive teaming arrangements can create competitive concerns. For example, if the merging parties have exclusively teamed with the leading suppliers of a critical component, the merger may eliminate competition between those teams and prevent potential competitors from gaining access to the critical component needed to bid for the program.

Example: During the Lockheed and Martin Marietta merger, each firm had an exclusive teaming agreement with a sensor provider for the Space Based Infrared System (SBIRS) new contract competition. These were the only two potential sensor providers available for the SBIRS contract competition, and so the teaming agreements, if enforced, would prevent other SBIRS bidders from having access to the needed sensor suppliers. To address this concern, FTC ordered that Lockheed and Martin Marietta could not enforce exclusivity provisions of their teaming agreements for the SBIRS contract competition.

\section{Compromising proprietary information}

The merger or acquisition of a firm's supplier by a competitor raises concerns about inappropriate use of the firm's proprietary information by the competitor in markets where the two firms compete. It may also raise concerns for the Department of Defense if the acquiring and newly acquired firms are both part of an upcoming DoD acquisition contract. The merged firm may be able to free-ride on its competitors' innovations, thereby reducing the competitors' incentives to innovate.

Example: A concern was raised during the acquisition of Hercules, a propellant and explosives supplier, by Alliant. Hercules, in its role as supplier, could receive proprietary 
information from Alliant's ammunitions and munitions competitors that Alliant could use in its ammunition and munitions division. The FTC required a firewall, directing that Alliant may not share proprietary information with its subsidiary that manufactures ammunition and munitions, absent written consent of the proprietor. Alliant may only use proprietary information in its capacity as a provider of propellant or explosives.

\section{Refusing to use suppliers owned by competitors}

After a merger or acquisition that restructures the vertical relationships between firms, competitors may be reluctant to enter into supply or teaming arrangements with the consolidated firm for fear that the firm could act to disadvantage its competitors. This effectively limits the competitors' supply options.

\section{Definitions}

For the purpose of this Task Force report, the following definitions are used.

Defense industry. Those firms engaged in supplying products or services for defense use, either by direct contract with the Department or as subcontractors to firms that directly contract with the Department of Defense. This report addresses the industry that provide integrated defense systems-for example, tanks, aircraft, ships, satellites-and the subsystems and components needed to build them. It is not intended to address common commercial commodities or services (e.g., petroleum, telephone services, construction services) procured by the Department of Defense, or vertical integration in those commercial firms.

Prime contractor or "Prime." A firm that furnishes products or services by direct contract with the DoD. In this report, a prime contractor is a firm typically engaged in providing complex, integrated defense systems. Prime contractors usually perform final assembly, integration, and test of defense systems for delivery to the Department of Defense. ${ }^{8}$

Supplier. Any supplier, vendor, or other firm that typically furnishes products and services below the integrated defense system level. Suppliers' products range from major subsystems to assemblies and components that primes need to build integrated defense systems.

\footnotetext{
$8 \quad$ U.S. General Services Administration, Federal Acquisition Regulations (FAR), http: //www.gsa.gov/far
} 
Subcontractor. A supplier becomes a "subcontractor" when the supplier is under contract to furnish supplies or services to or for a prime contractor or another subcontractor to the prime. Subcontractors are sometimes referred to as first tier, second tier, and so forth, to describe the number of subcontract levels below the prime contractor. ${ }^{9}$

Horizontal. Horizontal competition exists where two or more firms produce products in the same market, that is, products that address the same customer need or the customer would judge as acceptable substitutes. Horizontal mergers or acquisitions are those in which a firm gains new or additional businesses for defense products that could compete in the same market in which the firm already operates.

Vertical. A firm has vertical capabilities if it can provide input for its products from another business unit internal to that firm. Vertical mergers or acquisitions are those that add supplier product lines (components, subsystems) to a firm that also makes products at a higher tier. For example, if a DoD prime contractor acquires a business that makes components the prime needs for its integrated defense systems, it is a "vertical" acquisition.

"Make" item. An item or work effort produced or performed by the prime contractor or its affiliates, subsidiaries, or divisions. A "make or buy" decision is a firm's decision about whether to produce internally, or buy externally, an item or service needed for a product it sells to customers. ${ }^{10}$

Commercial item. Items offered or sold to the public in a commercial market.

$9 \quad$ lbid.

10 Ibid. 


\section{CONSOLIDATION HAS INCREASED VERTICAL CAPABILITIES IN SOME DEFENSE FIRMS}

\section{A. Major defense firms are diversifying}

Many major defense firms have more diverse capabilities-horizontal and vertical -as a result of consolidation. Firms appear to be pursuing horizontal strategies, rather than vertical integration strategies.

The ongoing defense industry consolidation was precipitated by the dramatic decline in the DoD budget. The procurement budget has had the sharpest drop, declining more than $65 \%$ since the peak of spending in the mid-1980s, and this most directly affects industry. The consolidation has been extensive, affecting business units involved in nearly every kind of major defense system (illustrated by Table 1 ). ${ }^{11}$

The defense industry has historically expanded and contracted over defense spending cycles. However, important differences in this cycle are stimulating more large scale industry consolidation than any since post-World War II.

- First, today there is a less clearly perceived or defined future national security threat. In contrast, after the Vietnam war spending decline, the Cold War threat remained as an investment focus.

- The U.S. government budget is also affecting the defense business outlook: The United States is currently pursuing a balanced budget, and the budget now offers a declining opportunity for increases in defense spending because of increasing nondiscretionary spending (e.g., Medicare). ${ }^{12}$

11 Source: Credit Suisse First Boston. Credit Suisse terms the current consolidation the "second wave" of consolidation, and terms an earlier set of more generally modest transactions in the 1980s as the "first wave."

Note: Dollar values for annual transactions are provided by Credit Suisse through 1994; dollar values for 1995-1886 are provided by DoD.

12 J. Lundquist, "Shrinking Fast and Smart," Harvard Business Review, November-December 1992, pp. 74-85. 
- Finally, because of increasing complexity, it costs more to develop and produce a defense system today than it did in the past. Given a comparable defense procurement budget level in constant dollars in 1976 and 1996, the Department of Defense could buy more units of a weapon system product (for example, fighter aircraft) in $1976 .{ }^{13}$

One effect of the consolidation is that some major firms, in becoming more diverse, now have increased vertical capabilities. The Task Force examined the breadth and mix of business units that have been combined under larger corporate entities as a result of mergers and acquisitions (see Table 1 for a partial listing). ${ }^{14}$ From this review, the Task Force found that many major defense firms have gained a more diverse set of businesses, and that the newly acquired business units often include those that have historically performed as a subsystem or component supplier. The Task Force is defining this increase in major defense firms' vertical supplier level capabilities as increased vertical integration.

The Task Force cannot assign a specific value or measure to this increased vertical integration, as it did not find a way to specifically measure its degree or scale, or to narrow it to a certain product area. Neither the industry analysts, antitrust agency representatives, nor members of industry who spoke to the Task Force said that they measure industry vertical integration, nor did they propose a mechanism to do so. ${ }^{15}$

Defense firms do not appear to be pursuing vertical integration as a purposeful strategy. More traditionally, firms may seek to vertically integrate by buying suppliers or distributors for process control or market position. For example, firms may acquire raw material suppliers or systems to distribute or sell their products, hoping to achieve efficiencies by coordinating internal processes, or ensuring high quality and uninterrupted supply from one part of their business to another. In such cases, firms may pursue vertical integration as a

13 Based on ODUSD(IA\&I) comparison of historical system acquisition costs.

14 Morgan Stanley Equity Research and Bear Stearns also provided data and a presentation to the Task Force on the business units involved in the consolidation.

15 Based on representatives' presentations to the Task Force and literature research. Antitrust agencies do use an index, the Herfindahl-Hirschmann Index (HHI), as a measure of horizontal competition concentration in a particular market (this is only one consideration in horizontal merger reviews). The HHI is calculated by summing the squares of the individual market shares of each participant. While horizontal concentration is a factor in vertical cases, it is only one factor among many. The 1984 Merger Guidelines, used by the antitrust agencies use to assess vertical cases, provide no index or measure of vertical integration. 
strategy because, given their product and overall industry, they believe it may increase their internal efficiencies. ${ }^{16}$

In contrast, the increase in vertical integration in defense firms appears to be a collateral effect of firms' strategies motivated by other consolidation goals. ${ }^{17}$ In this consolidation, defense firms are generally acquiring (or merging with) other firms that have been producing a variety of defense products, including some lower-tier products such as subsystems and components.

Defense firms are seeking to increase revenue by buying other firms" existing or "backlog" orders, to improve profit margins and stock market performance, and to reduce excess capacity. They are also diversifying their product lines to increase opportunities for future sales. They may act to "buy now" if attractive or important businesses become available, in part to deny them to competitors. Finally, many defense firms are buying electronics and software integration capabilities. While electronics and software capabilities may be particularly judged as vertical additions, firms may see these as a key to future system integrator capabilities, or simply as the potential growth market in defense.

Vertical integration in defense also has an upward "system of systems" dimension. The Department of Defense tasks prime contractors to define top-level designs and to integrate multiple systems and subsystems to function together to provide required mission performance. Traditionally, different primes specialized in various system areas. Through consolidations, some prime contractors are now gaining capabilities that represent an interrelated system of systems; for example, a firm might own businesses in space launch, launch ground services, satellites, and related ground and airborne communications and control links. The insights and capabilities gained with a range of interrelated systems businesses can be synergistic and can also provide advantages to the firm bidding for work in any one of the related systems product areas.

These forms of vertical integration are not a new phenomenon in the defense industry. However, they are increasing as the consolidation concentrates defense product lines in fewer firms.

16 The question of firms using vertical integration as a strategy to gain internal efficiencies is a subject of substantial research and history in itself, and is not addressed by this report.

17 Morgan Stanley Equity Research, presentation to Task Force, September 20, 1996, observations also supported by industry presentations to the Task Force. 


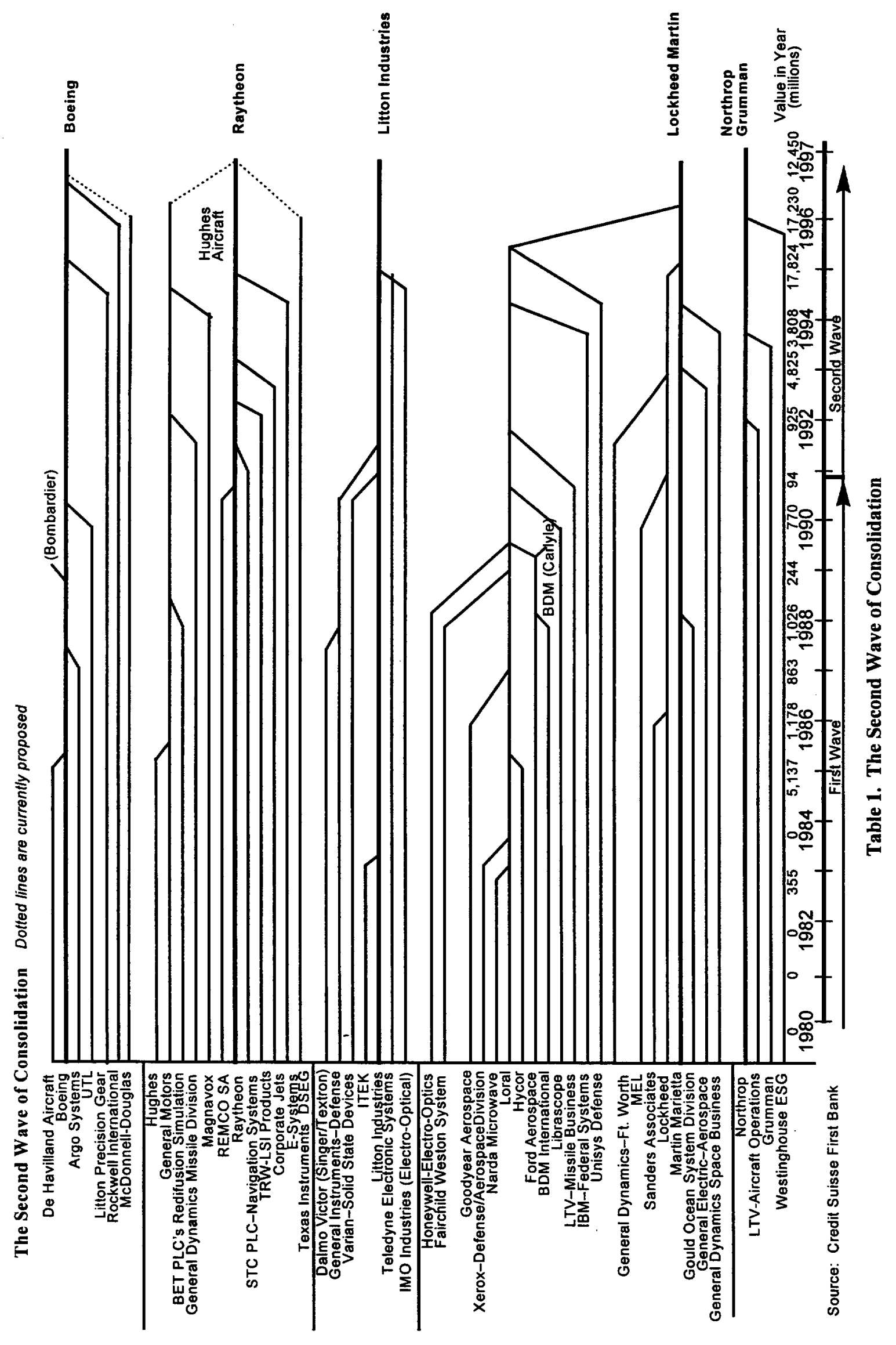




\section{B. Further consolidation effects on vertical integration are unclear}

$$
\begin{aligned}
& \text { Market realignments may continue, but firms have incentives to hold on to } \\
& \text { important or discriminating vertical capabilities they have acquired. }
\end{aligned}
$$

In response to the budget decline, firms have also been taking dramatic steps to re-structure, including reducing excess capacity and personnel and re-engineering internal processes towards more "lean" operations. Some analysts suggest that firms have also been reducing capital expenditures and research and development (R\&D) investments. ${ }^{18}$ Many defense business units today have high market valuation that can make them attractive candidates for divestiture by the selling firms. ${ }^{19}$

Overall, the stock market is rewarding firms that consolidate, trim excess capacity, and increase efficiencies. The potential for firms to grow their value through consolidation is evidenced by the continuing consolidation activity among major firms underway as this report is being completed. Notably, pending at this time are proposed mergers of Hughes Aircraft and Raytheon ( $\$ 9.5$ billion); Boeing with McDonnell Douglas ( $\$ 13$ billion); and the acquisition of Texas Instruments Defense Systems and Electronics group by Raytheon ( $\$ 2.95$ billion). These proposed transactions, which would combine firms that are horizontal competitors in some areas, could result in increased vertical integration in some product areas if they are fully consummated.

Many large industry transactions are very recent. There may be further realignment of supplier-level (subsystem, component, etc.) business units as larger firms adjust their organizations to focus on their core business areas. The breadth and mix of assets acquired in many consolidations to date are leading many analysts to project a further consolidation phase of "portfolio shaping" beyond the current large transactions. Firms might swap or spin off assets obtained in previous transactions to focus on their "core" areas. However, with limited opportunities in new defense program sales, and in the absence of an altered security threat, it is unclear that firms will sell or divest "vertical" businesses involving important or

18 Ibid. However, DoD's records of firms' internal R\&D (IR\&D) investments/sales (percentage) did not show a decline as of 1995.

19 Ibid. Notably this has changed since 1991-92, when the current defense industry consolidation started and firms had relatively low market valuations. 
discriminating product and technologies. Portfolio-shaping actions to date are modest "fine tuning"; for example:

- General Dynamics acquired two Lockheed Martin units (\$450 million) and the Teledyne Vehicle Systems business. The acquired businesses make combat vehicle components and gun systems. These were modest divestitures for Lockheed and Teledyne, and good fits with General Dynamics' tracked vehicle business. These were also a strategic purchase for General Dynamics: The former Lockheed and Teledyne units, along with General Dynamics Land Systems, hold three of four major workshares of the Crusader program. (United Defense Ltd. Partners, the prime contractor, holds the fourth.) ${ }^{20}$

- Lockheed Martin recently announced the spin-off of ten "non-core" business units into a new firm, L3 Communications, of which Lockheed will hold a 35\% share. ${ }^{21}$ The Task Force viewed the ten units (for example, microwave antenna, chaff and flare dispensers) as representing a very modest spin-off of technology capabilities from Lockheed.

\section{Budget declines are reducing DoD's supplier base}

Reductions in the supplier base are largely a result of DoD budget declines, not of prime contractors' vertical integration.

Although the defense industry has expanded and contracted with defense spending cycles, a viable supplier base has historically been available when needed. ${ }^{22}$ The decline in the

20 General Dynamics' acquisition of the Lockheed and Teledyne units may add some vertical capabilities to the corporation, but it may also make General Dynamics a stronger potential competitor to UDLP in future light armored vehicle programs.

${ }^{21}$ J. Mintz; "Lockheed Martin Will Spin Off 10 Divisions," Washington Post, February 4, 1997, p. C1.

22 Numerous sources resulting from literature research, summarized in R. Read, S. Nash, and C. Fisher, Summary of Research on Sub-tier Suppliers, ODUSD (IA\&I), December 1996. While important supplier capabilities have been available across budget cycles, there may be a leadtime to establish needed additional capacity. 
number of subsystem or component level firms supplying defense in the last few years is due to spending declines, along with defense firms' purposeful strategies to increase efficiency by limiting their preferred suppliers. ${ }^{23}$ At this time, evidence does not indicate that the primes' increased vertical integration is reducing the number of suppliers. ${ }^{24}$

Very few, or sole source, suppliers may be inevitable in some very low-volume, highly unique areas. Severe reductions in the numbers of suppliers can lead to loss of price and or technological competition; such areas have always required special DoD attention, regardless of the structure of the firm in which they reside.

As mentioned previously, the Department of Defense has a policy and process in place to identify and address critical defense industrial capabilities that are endangered due to the loss of suppliers.

${ }^{23}$ P. Finnegan, "U.S. Supplier Base Feels Bite of Consolidation," Defense News Survey, Defense News, July 31-August 6, 1995. Defense News Survey reported "...74\% of U.S. primes said key subcontractors were leaving the defense business."

24 Numerous sources, summarized in Read, Nash, and Fisher, op. cit. 


\section{VERTICAL INTEGRATION DOES NOT APPEAR TO BE A SYSTEMIC PROBLEM TODAY BUT WARRANTS CAUTION}

To date, several defense mergers and acquisitions have posed potential vertical concerns, and remedies have been put in place by the antitrust agencies. The Task Force did not find substantial evidence that firms' business practices on current DoD programs have changed as a result of their increased vertical capabilities. However, many mergers and acquisitions are very recent. In the short term, cost and risk create powerful incentives that discourage firms from switching suppliers on established programs.

\section{A. Some defense mergers and acquisitions have posed vertical integration concerns}

More remedies ordered in defense industry antitrust reviews since 1994 have addressed vertical, rather than horizontal, concerns.

The Task Force identified thirty-four defense mergers and acquisitions that were consummated from 1994 through March $1997 .^{25}$

- The Department of Defense supported the antitrust agency reviews in approximately twenty of these cases.

- In eight of the thirty-four transactions, the antitrust agency issued consent orders.

- Vertical concerns were included in seven of these eight consent orders, a significant occurrence. ${ }^{26}$ Four of the cases resulted in a consent order for a horizontal concern. ${ }^{27}$

25 The number of cases (thirty-four) is a count of notable cases and does not represent all transactions that were proposed or consummated or the number of cases examined by antitrust agencies. Appendix D, "Defense Industry Antitrust Reviews," lists the thirty-four cases and the transaction values.

26 However, this percentage of cases reviewed and vertical concerns remedied cannot be fairly compared with other industries because of the defense industry's unique characteristics and its degree of concentration.

27 The four horizontal consents concerned were Lockheed/Martin Marietta (SBIRS program); Hughes/Itek (Airborne Laser program); Boeing/Rockwell (unmanned aerial vehicles); and Lockheed/Loral (satellites, primarily commercial). 
The predominant vertical concern, addressed in seven of the eight consent orders, was potential compromise of proprietary information. These are cases where the firm gaining a new business unit may also gain sensitive information about a rival the new unit historically supplied. Antitrust agencies ordered a remedy for concerns of vertical foreclosure in one case. ${ }^{28}$ Section IV of this report describes the antitrust review process, and results of antitrust reviews for defense industry from 1994 to the present.

\section{B. The Task Force found limited evidence of problems}

Firms provided little evidence that industry business practices have changed due to vertical integration, but some feel the potential for harm is real.

Based on industry representatives' presentations and limited data available, the Task Force did not find significant evidence that firms are currently employing vertical capabilities to Department's disadvantage. A few industry representatives provided anecdotes of defense firms using vertical capabilities to disadvantage other firms. These anecdotes portrayed two basic problems:

- A firm was unwilling to buy from, or sell important or discriminating technologies or products to, a rival firm (for a variety of possible motives), and

- A prime firm excluded subtier suppliers from a new weapon system solicitation, presumably due to the existence of, and preference for, internal capabilities.

Firms can behave in an exclusionary manner whether or not they become vertically integrated as a result of a merger or acquisition. Some Task Force members provided anecdotes of firms' past exclusionary behavior, which was unrelated to new mergers or acquisitions. ${ }^{29}$

Most presentations to the Task Force reported concerns about the potential for problems to arise from more vertical integration, rather than the current incidence of such problems. These fears may be based on past experience with other firms' exclusionary actions, and the concern that vertical capabilities and the current environment make such actions more likely. Various forms of technical foreclosure, such as those the firms described in their anecdotes of current problems, were foremost among potential concerns. Representatives of supplier

28 FTC was concerned about potential vertical foreclosure in the Lockheed Martin Marietta merger relative to exclusive teaming agreements; Table 6 in Appendix D, "Defense Industry Antitrust Reviews," for details.

29 Confidential communication of Task Force members and speakers. 
firms (firms who have a primary role as a subtier supplier of subsystems, components, etc.) tended to be more pessimistic about the negative effects of vertical integration than firms in a predominantly prime contractor role.

There is evidence that prime firms in seriously distressed industries may adopt a more purposeful strategy to bring work in-house to assure supply. ${ }^{30}$ This trend was also evident during the defense budget decline of the 1970s, but in the cases reviewed, the prime brought work in-house due to a specific supplier problem (for example, performance, bankruptcy, or decision to leave the market). ${ }^{31}$

In most of these cases the prime eventually qualified a new external source. It is impossible to speculate whether primes would have kept more work in-house in the 1970s if firms had viewed market conditions as pessimistically as they do the current market.

The Task Force noted there has been an undercurrent of concern expressed by firms in the press. Lockheed Martin's CEO, Norman Augustine, has stated that if prime contractors act on their new vertical capabilities to "freeze out competitors' key product access or to shut out second and third tier suppliers," it would tend to "unfairly favor the largest suppliers with the broadest component and technology base. As such this is a trend about which our government...should be evidencing a great deal of concern." 32

During proposed industry transactions, several firms have publicly expressed concern about being denied access to supplier capabilities critical or discriminating to their products. For example, during the Lockheed Martin acquisition of Loral, McDonnell Douglas's CEO Harry Stonecipher noted that "we will have to find other suppliers that can not only supply us the best products, but also help us sell our platform." ${ }^{\text {"33 }}$ An industry analyst said this "...is a trend to watch," noting that "other companies are concerned over what Lockheed Martin's merger with Loral means for the industry."34 More recently, Northrop Grumman expressed concerns

30 For example, DoD representatives reported to the Task Force that in 1993-94, Westinghouse brought torpedo propulsion work in-house after the supplier was having problems. As DoD is not planning new torpedo procurements, Westinghouse likely did this to assure supply for their committed production work, and not to vertically integrate into the torpedo propulsion market.

31 G. Baumbusch and A. Harman, "Peacetime Adequacy of the Lower Tiers of the Defense Industrial Base," Rand Corporation Report R-2184/1-AF, 1977.

32 N. Augustine, "Unhappy Birthday: American's Aerospace Industry at 100," Aerospace America, February, 1997, pp. 24-31.

33 R. Holtzer, "McDonnell May Find Lockheed Martin Difficult to Ignore," Defense News, April 29-May 5, 1996, p. 28.

34 Ibid. The article quoted B. Callon, an analyst with Merrill Lynch, Pierce, Fenner, and Smith Co., New York. 
about the effect on airborne radar competition of the proposed acquisition of Texas Instruments Defense Systems and Electronics Group by Raytheon, Northrop Grumman's competitor in this area. ${ }^{35}$

This undercurrent raises public speculation that vertical integration is causing problems today, but the evidence presented to the Task Force could neither fully confirm nor deny such concerns. It is difficult to discern if this undercurrent reflects existing problematic industry practices, or firms' fears about potential problems. Further, firms could raise fears or potential concerns to the public in an attempt to block mergers or acquisitions that may be particularly advantageous for their competitors. Antitrust agencies and the Department of Defense review market conditions and assess concerns expressed by firms during the antitrust review process to determine if there is a potential for competitive harm. There is no indication that this review process is not working well.

\section{In existing programs, the cost of switching suppliers mitigates vertical integration tendencies}

Task Force review of some DoD programs suggests firms are not altering their
buying decisions to favor internal businesses, but the industry consolidation is
too recent to measure or predict its effects on firms' make or buy patterns.

Traditionally, firms tend to maintain stable sources of supply once established on a program. In the experience of many Task Force members, prime contractors avoid changing important suppliers on an existing program unless provoked by a problem (for example, poor performance), in part because changes can create risk and cost. Change more often occurs at lower component levels: as design for parts change or become obsolete, primes must find new sources. DoD program managers are often motivated to keep the experienced team in place, especially in transition from development to production and in major system upgrades.

In $\mathrm{DoD}$ programs already in development or production, primes appear to be continuing to buy from their current suppliers, regardless of their acquisition of new vertical business units. The Task Force heard presentations from the New Attack Submarine, Aegis Destroyer, and F-22 aircraft program offices, and reviewed data on primes' "make and buy" content in the

35 J. Cole and J. Wilke, Wall Street Journal, February 14, 1997. The Northrop Grumman spokesman declined to elaborate. The authors reported that "other people following the developments said Northrop Grumman is vigorously protesting the issue [Raytheon/Texas Instruments] to regulators." 
F-18 C/D and E/F, the F-22, and Joint Strike Fighter aircraft programs. DoD program managers stated that they have not observed prime firms reversing "buy" decisions on current programs.

The Task Force obtained data for a small number of programs representing a cross-section of product life phases. While the data were not conclusive, there appeared to be little difference in firms" "make" percentage (internal value as a percentage of the total program) between firms with newly acquired vertical business units and firms that had not recently acquired vertical business units. Firms that had newly acquired vertical capabilities did not appear to change notably the type of products they are providing on the program, or their overall "make" percentage of program value. Appendix E provides some details of data provided by the F-18, F-22, and Joint Strike Fighter program offices.

Data from the Joint Strike Fighter program on the prime contractor's "make" value were inconclusive, as the Department of Defense just awarded a preliminary development contract in November 1996 and firms have not made many supplier decisions. Also, the Joint Strike Fighter office is funding several contracts for "technology maturation" in important areas that they awarded separately from the prime contract. The primes will select suppliers for those areas later, as the results of the maturation programs emerge.

\section{Vertical integration poses potential future concerns to DoD}

Increased vertical integration may result in a less competitive marketplace for important or discriminating defense supplier level products

While evidence reviewed by the Task Force does not show vertical integration to be a systemic problem today, the Department of Defense should be concerned about the potential effects of vertical integration in new and future defense products, upgrade programs and logistics services. Many major mergers and acquisitions are too recent for their vertical effects to be apparent. The DoD budget decline and the resulting industry consolidation have created new conditions that could change incentives for firms to employ vertical integration to their advantage. These incentives may not foster "best value" bids to the Department of Defense, or a long-term competitive, innovative supplier base.

\section{INDUSTRY CONDITIONS HAVE CHANGED}

As a result of the reduced DoD spending and the industry consolidation, the defense industry is more concentrated. There is a smaller number of contractors for many DoD product areas, 
and many of the prime contractors are more vertically integrated. This is not likely to change soon. Table 2 reflects the total number of firms who represent two thirds (about $66 \%$ ) of defense product sales annually, and how this total number has changed over time. ${ }^{36}$ Pending transactions between Boeing/McDonnell Douglas, Raytheon/Hughes and Raytheon/Texas Instruments, if fully consummated, would result in further concentration, as four of these firms are among the top eight firms in 1995.

Table 2. Firms with Top Two-Thirds of Defense Product Sales*

\begin{tabular}{|cc|}
\hline Year & Number of Firms \\
\hline 1987 & 15 \\
1989 & 17 \\
1991 & 15 \\
1993 & 13 \\
1995 & 8 \\
\hline $\begin{array}{l}\text { Source: } \text { DoD analysis derived from Defense Contract Audit } \\
\text { Agency database. *Numbers are based on the total prime and } \\
\text { subcontract sales for each firm in the database. }\end{array}$ \\
\hline
\end{tabular}

Newly consolidated primes now have a much broader portfolio of weapon system product lines, offering broader internal vertical supply opportunities. With fewer new DoD programs, firms are motivated to secure the maximum possible market share in each part of the broad range of their portfolio.

At the same time, as a result of personnel reductions and reforms in DoD acquisition practices, the Department is reducing its monitoring and management of operational details of its acquisition programs. It may have difficulty identifying evidence of a growing vertical integration concern, particularly in more subtle forms.

Defense product sales data are drawn from a Defense Contract Audit Agency (DCAA) historical database and are based on company-reported sales accounting data. This database includes sales of all firms that have auditable DoD costs over $\$ 70$ million for the fiscal year, plus all firms who have claimed $\$ 10$ million or more in defense IR\&D costs. Given these criteria, many firms who sell common products or services to DoD that are not of interest to this study are typically excluded from this data, such as construction, transportation, telephone, insurance, medical services, petroleum, etc. Thus, these data include firms' sales of defense products but it does not represent all sales to DoD, or all firms selling to DoD. The number of firms in the chart for a given year is that number of firms whose sales represent two-thirds of all sales to $\mathrm{DoD}$ in the database in that year. Note that in any one particular defense product market there may be more or fewer firms who compete than the number reflected in this table. 


\section{NEW INCENTIVES POSE POTENTIAL VERTICAL CONCERNS}

As new programs, procurements, or other opportunities present themselves, firms could act more strategically upon their vertical strengths.

Vertically integrated firms could decide to expand in-house capabilities, add new core competencies, improve their market position, or increase profitability in product areas they formerly purchased outside. Firms could now divert investments to build in-house business units, where they might formerly have invested to build external suppliers' capabilities. It is fair, and a normal business practice, for firms to leverage their internal capabilities, and to employ them in their products when they are the best value solution. However, if vertically integrated firms use internal supply capabilities in ways that decrease competition at supplier levels below the prime, the Department of Defense risks losing innovation and price benefits of market competition at the integrated defense system level as well.

\section{Firms could build vertical strength to exclude other suppliers.}

To develop their internal businesses, prime contractors may favor their new in-house capabilities over external suppliers in new weapon systems bids. In building teams for new bids, primes could elect not to solicit suppliers at all in areas where they have internal potential. "It [vertical integration] might allow prime contractors to shut out traditional second and third tier component suppliers who, operating at the lower end of the manufacturing "food chain," normally sell to primes.",37

Primes could use internal capabilities as leverage with suppliers. They might compete internal sources against suppliers to squeeze costs, or use leverage to force suppliers to absorb a greater share of development costs. Medium- or smaller-size firms who have traditionally performed defense value-added work may need to keep a clear technology edge or serve a unique niche to be attractive. These firms may have less ability to cross-subsidize their product lines than diverse primes, and might be particularly "squeezed."

Other factors (cost, technology, quality) being roughly equal, primes might prefer to employ in-house sources of supply to increase overall corporate value-added work, especially in costplus work. In so doing, firms would weigh the cost and profit of internal versus external

37 N. Augustine, op cit. 
sourcing in light of the Federal Acquisition Regulation profit provisions. These provisions require firms performing government contracts to transfer products from one division to another within a firm at cost, rather than cost plus profit. ${ }^{38}$ This provision of contracting with the Department of Defense may promote an incentive for firms to externally source in certain situations. ${ }^{39}$ Firms might also "cherry pick" the highest value, most sophisticated work for their in-house suppliers to build corporate skills, leaving routine, lower-margin areas for external suppliers.

Primes may view external suppliers with suspicion if they are on more than one prime's team, particularly where the supplier has access to the primes' proposed system design. The need for close working relationships, access to critical knowledge and skills, risk sharing, and proprietary information partnerships may drive firms into long-term real or virtual teams. A supplier may gravitate to a single prime and no longer concentrate on supplying other primes (equally aligned with their supplier), creating a kind of de facto vertical integration, with or without actual ownership.

\section{Firms could use vertical strengths to disadvantage their competitors.}

Vertically integrated primes may deny competing primes access to key products or technologies they formerly supplied, or may give them access to a lower performance or higher cost product. Further, prime contractors have stated they are less likely to use a (vertically integrated) rival as a partner or supplier on important new programs. ${ }^{40}$ They are also worry that in supplying a rival, the best technology, fastest cycle time, and lowest costs would accrue to the (rival) owning prime. Exclusionary actions tend to spawn retribution by other firms in future program decisions. component at a higher cost than the price charged by the outside supplier, and does not otherwise have
pressures driving lower cost "make or buy" decisions, the vertically integrated firm may have the incentive to produce the component internally and earn a profit on the higher price.

40 C3. During the Lockheed Martin acquisition of Loral, McDonnell Douglas's CEO, Harry Stonecipher, said they may elect to use other suppliers rather than rely on rival Lockheed in future weapons bids. Mr. Stonecipher told reporters he expects subcontractors - as Loral had been for McDonnell - to be full partners in promoting the McDonnell solution in critical new programs such as Joint Strike Fighter, "something Loral divisions probably couldn't do when owned by Lockheed Martin, which is offering its own plane in the competition." 
Today's environment is highly cost driven for firms bidding on DoD programs. In the defense industry, teams of firms share resources and designs, and trade requirements against cost in preparing bids to the Department of Defense. The cost environment compels primes to seek major partners and suppliers willing to share the investments required to pursue new programs. Investment sharing is not likely to occur if a prime seeks to include vertically integrated elements of another prime competing on the same program.

Firms are also concerned about sharing insight that reveals their system designs to suppliers who work for rivals. It is a normal industry practice for firms to develop legal agreements with each other to maintain confidentiality of information obtained in close working relationships among their respective operating divisions or units. These company-initiated agreements may help offset some concerns that firms may have in employing their rivals as suppliers.

\section{Primes could exploit their designs to promote vertical strengths.}

Since prime contractors define defense system designs, they could use the design process to promote their internal capabilities, further limiting external supplier opportunities. Depending on how primes divide the functions in a new design, functions once provided by suppliers may now become part of a different component or assembly-one that the prime provides. In such cases, suppliers may not have visibility and access into primes' new design opportunities.

High development costs for new systems and the increasing need for complex electronic and software system integration demand very close teamwork and proprietary data-sharing between prime and suppliers. Some technological advances, such as stealth or embedded sensors and antennas, require a subsystem design that is literally interwoven in the system design. ${ }^{41}$ These factors may encourage or allow primes to favor internal sources in a way that may be difficult for DoD managers to perceive. At the same time, vertically integrated firms may be able to develop and produce these integrated designs more efficiently, and they may pass along these efficiencies to the Department of Defense in product competitions.

As primes create overall system architectures for new DoD weapon system programs, they may gravitate to their in-house subsidiaries early in the program life. This in-house

41 For example, in a presentation to the Task Force, one supplier said that his firm traditionally supplied devices that attach missiles and bombs to aircraft and activate them when launching. In a new generation system, the prime defined these devices to be internal to the aircraft structure and they became a "make" instead of a "buy" item for the prime. 
preference naturally results from the primes' desire to build on their proprietary knowledge and strengths. Primes could make subtle technical choices that advantage internal capabilities that DoD personnel, even if involved in architecture approval, may not recognize.

Table 3. Pressures Mitigating and Encouraging Harmful Effects from Vertical Integration*

\begin{tabular}{l} 
a. Mitigating \\
$\begin{array}{l}\text { Short Term } \\
\text { Costs to switch from external to internal supply } \\
\text { sources } \\
\text { Active prime level or horizontal competition } \\
\text { Long Term } \\
\text { Active prime level or horizontal competition } \\
\text { DoD use of commercial products and processes } \\
\text { Effective DoD open architectures } \\
\text { Firm's outsourcing (cost pressure) } \\
\text { Firm's divesting business units to alter focus, or } \\
\text { for other business reasons } \\
\text { FAR profit rules (allowing cost, not cost plus } \\
\text { profit, on interdivisional sales) } \\
\text { Changes in technology and defense missions }\end{array}$ \\
\hline${ }^{*}$ List not exhaustive
\end{tabular}

\section{b. Encouraging}

Less active prime level competition (fewer than three viable prime-level competitors)

Firm's desire to capture maximum profit or shareholder value

Firm's desire to capture maximum growth in technical capabilities, diversity, market share Firm's desire to retain key skills or performance capabilities across a "lean" sales period

Firm's desire to have maximum control over risk or quality

Firm's desire to capture or keep leading technology or product position in key areas Firm's desire to have a larger base for overhead cost absorption

Highly integrated system and subsystem designs

\section{E. Some pressures mitigate vertical integration concerns}

Some market pressures mitigate vertical integration tendencies, but these pressures may not be adequate safeguards to protect the Department's interests.

Vertical integration carries with it some significant operational and market problems that mitigate some of the concerns addressed above. Because of these problems, firms have incentives to make their newly acquired vertical businesses compete for internal work, or to shed some new vertical businesses entirely. To the degree that the Department can foster 
these mitigating market pressures, described below and in Table 3, it can lessen the potentially harmful effects of vertical integration.

However, limited DoD spending, few new programs, and a very concentrated industry imply a potentially static business environment that warrants DoD caution regarding vertical integration. The Task Force concluded that, in the current environment, these counterpressures to vertical integration may not be adequate safeguards to ensure the Department's interests in maintaining a competitive and innovative supplier base are met.

\section{DOD-PROMOTED COMPETITION}

DoD policies and practices that encourage competition in the defense industry can help counteract vertical integration concerns. Prime-level competition promotes best value for the Department, although it does not ensure it. Firms reported to the Task Force that reduced opportunities for new programs, and the Department's increased emphasis on reducing cost, have created an intensively competitive bidding atmosphere. Intense competition means that prime contractors cannot risk losing an entire program by relying on inferior subsystems or components, regardless of the source or of their vertical capabilities.

The Department's emphasis on "best value" prime bids, coupled with a sense of vigorous prime-level competition, may also encourage companies to keep their internal supplier businesses competitive. If a firm's internal business must compete with external suppliers, the market helps provide cost and technology discipline to that internal business. For example, if there is active competition between suppliers internal and external to a vertically integrated defense systems integrator, the Department of Defense may have less concern that vertical integration could harm defense product cost or innovation. ${ }^{42}$

Firms in many other industries-computer, automotive, for example-are trending towards increased outsourcing for cost control and efficiency. ${ }^{43}$ To the extent that the Department of Defense effectively creates competitive pressures, defense firms may increasingly adopt this practice.

However, the Department cannot expect the defense industry, especially in its current concentrated form, to fully operate as a commercial marketplace. The limited new opportunities for defense firms exacerbate the potential for some competitors to leave the

42 However, vertically integrated firms could still elect to use internal supplier capabilities preferentially, potentially harming competition and innovation over the long run.

43 J. Lundquist, McKinsey and Company, presentation to DSB Task Force, September 19,1996. 
market. When the Department makes a major, or the only foreseeable, contract award in a given product area, losing firms must reassess whether they can sustain their business in the face of limited new potential sales in that area.

\section{MisSION AND TECHNOLOGY DYNAMICS}

Vertical integration could be a transitory state of the defense industry, particularly at the leading technology edge. Continuous change in missions and technologies for defense systems makes fixed, in-house investments in supply (component or subsystem) subsidiaries risky. Firms may be cautious about relying on a business strategy based on a "top to bottom" in-house supply chain that may become obsolete as new technologies replace old ones. Firms that rely on internal supplier capabilities also run the risk of losing touch with advances in the market or of pursuing technological blind alleys. Some advanced electronics component technologies, for example, last only three to five years before being replaced. As today's systems mature and requirements for their production wane, prime contractors may try to justify replacement products (rather than upgrades) by defining systems that incorporate substantial new technologies. This could further speed up the rate of technological obsolescence.

As missions and technologies change, the roles that defense primes see as critical for their preeminence also shift. Future systems integrators may be firms that define system architectures and information concepts rather than firms with fixed hardware production capabilities.

However, the time horizon for such effects may be too long to offset near-term pressures towards vertical integration. Currently, the Department does not have a fast-changing threat. The nature and focus of the Department's science, technology, and development investments will largely set the pace of technology in the near term, with some contribution from its use of commercial technology.

\section{CORPORATE ENVIRONMENT}

Newly consolidated firms may not employ their new vertical (internal) supply capabilities preferentially, or may ultimately divest them, because of the dynamics of the combined companies. Large corporations sometimes lack a consistent corporate view throughout their diverse business operations. Economic incentives may at times encourage "sister divisions" to have different goals. Systems integration divisions seek "best value" supplier selections while supplier divisions pursue their own financial goals. Corporate leaders may have a 
policy to make fully competed supplier choices, but their subordinate divisions may act on local economic incentives.

Many firms with vertical capabilities, in both commercial and defense industries, aggressively compete in-house units with outside suppliers to assure lowest cost, best technology, and highest quality. In-house suppliers are often not the winners.

Over time the post-merger firms may divest or realign business units to focus on core businesses, or shed those subsidiaries that have not prospered in their new homes. Mergers and acquisitions are costly and many "fail" by some measure, for example, shareholder returns erode, or non-acquiring firms outperform acquiring firms. ${ }^{44}$ There is nothing to suggest that defense firms' mergers and acquisitions will enjoy a higher success rate than those in other industries. However, the static future defense spending profile and limited new program opportunities may not encourage significant shifts in important vertical technology or product portfolios in the near term.

\section{DOD ACQUISITION REFORMS TO ENCOURAGE MORE SUPPLIERS}

The Department of Defense's acquisition reforms and initiatives to increase use of commercial products, open systems architectures, and reliable foreign suppliers may help over time to offset the effects of a more concentrated defense industry by encouraging additional suppliers to participate in the defense market.

These reforms to expand its use of commercial suppliers and standards appear to have effectively broadened the suppliers available to provide components and assemblies to the Department. However, they have not yet significantly broadened the base of suppliers that contribute important defense engineering value-added products. At the same time, multiindustry/commercial firms continue to divest defense units, so that defense engineering value-added markets are becoming more concentrated in firms focusing primarily on defense.

The Department applies the largest share of its new program dollars to products or technologies that push state-of-the-art performance-by definition, products engineered beyond most current commercial needs. In the long term, the Department may be able to expand its commercial supplier base in additional product areas. However, unique

44 P. Zweig, J. Perlman Kline, S. Anderson Forest, and K. Gudridge, "The Case Against Mergers," Business Week, October 30, 1995. Some reasons for failure include lack of compelling strategic rationale, unrealistic expectations of synergy, paying too much, conflicting corporate cultures, and failure to move quickly to meld the two firms. 
performance requirements and low production volumes will preclude commercial sources of supply for some critical defense subsystems and components.

The Department of Defense has also removed several DoD-imposed restrictions to allow reliable foreign firms to supply defense programs in some areas. Further, the Department has been encouraging cooperative development programs with U.S. allies in order to leverage our mutual investments and capabilities. These steps may, over time, increase the suppliers available to participate in U.S. defense markets, but the Task Force did not examine this in sufficient depth to observe their current or likely effects.

The Task Force also looked at the Department's open system architecture initiative. In new development and some upgrade programs, the Department is requiring its prime contractors to define an open system architecture as a part of their design approach for system electronics. In an open system architecture, the system designer defines system interfaces to a set of standards that a number of suppliers agree to meet. This makes supplier products more interchangeable in the design, and so allows a wider range of suppliers to participate in defense systems. However, many current open systems definitions in DoD programs appear to be relatively system or company specific; this may limit the program's attractiveness to the broadest supplier base possible. DoD open systems must incorporate commercial and other widely used product standards; otherwise contractor-unique "architectures" will result. This could essentially equate to a unique system design and may advantage the prime contractor's in-house capabilities.

In applying open systems, the Department of Defense should also take steps to ensure the prime contractor does not have overriding open architecture ownership, knowledge, or control, as primes could exclude or limit the ability of many firms to participate. DoD managers need to work with industry to shape broad-based architecture definitions. The Joint Strike Fighter program office, for example, is trying to avoid this problem by managing its open architecture development through a working group comprising a wide range of company, industry association, and DoD technical personnel.

Open systems architectures may become an increasingly positive contributor to competition in those DoD programs where it is effectively implemented. However, DoD's applications are too new for the Task Force to measure their effect today. 


\title{
IV. HOW DOES DOD DEAL WITH VERTICAL INTEGRATION?
}

DoD affects vertical integration in two ways:

1. Using the antitrust review process to identify and remedy concerns about a proposed merger or acquisition, where appropriate, to minimize the potential for vertical integration problems due to industry consolidation.

2. Using ongoing DoD acquisition management processes - technology and acquisition strategies, decisions, and investments-for supplier visibility and to head off vertical integration problems.

The Task Force believes the Department of Defense would best serve its needs by focusing on fostering a competitive environment and preventing problems, rather than "fixing" problems by intervening in programs or making additional investments. The Department has less leverage and potentially fewer options if it must address problems that have already occurred. To act appropriately in reviewing proposed mergers and acquisitions, and in managing DoD acquisition programs, the Department needs adequate supplier insight and knowledge. This section describes how the Department antitrust and acquisition processes work today and how they address vertical integration.

\section{A. DoD's process to review mergers and acquisitions is appropriate for vertical issues and is working well}

\author{
The antitrust agencies and the Department of Defense are effectively \\ addressing vertical concerns through a flexible and well-coordinated antitrust \\ review process.
}

\section{ANTITRUST AGENCY AND DOD REVIEWS ARE COMPLEMENTARY}

FTC and DOJ are responsible for the antitrust review and decisions. The Department of Defense provides important insight and input, but the antitrust agencies make the final decisions about whether to order actions or block a merger under antitrust statutes. Both the antitrust agencies and the Department appear to be effectively assessing proposed transactions and satisfying their respective needs and responsibilities, without unnecessary duplication. To date, in the particular mergers that have been reviewed, the antitrust agencies 
and the Department of Defense have agreed on what areas would have created problems and what remedies were appropriate.

\section{Antitrust agencies lead the formal review}

The overall process for reviewing proposed mergers and acquisitions is the same, whether the merger is "horizontal" or "vertical" in nature. The agency review typically begins with a firm's Hart-Scott-Rodino filing with FTC and DOJ. The agency designated to address a given case will contact the merging parties, customers, and competitors to better understand the industry and the effect of the transaction. Within thirty days, the agency must decide whether to issue a Request for Additional Information (a "second request"). Firms cannot proceed with the transaction until they have complied with the second request, if issued. Once the parties comply with the second request, the agency generally has twenty days to decide whether to attempt to block the transaction.

\section{DoD looks at effects on defense products.}

As the single customer for most products of the defense industry, the Department of Defense is vitally concerned about the potential effects of mergers and acquisitions. The 1994 DSB Task Force found that "DoD's knowledge of the defense industry and its unique perspective on the health of the industry...can contribute to the informed review of proposed transactions. ${ }^{~} 45$ In keeping with the 1994 Task Force recommendation, DoD established an internal review process "to assess the potential effects on DoD programs that might result from a proposed merger or acquisition. ${ }^{946}$

While the antitrust agencies conduct their review, the Department conducts its own. This review is led by USD(A\&T) and the DoD General Counsel, in accordance with DoD Directive 5000.62. The DoD review typically begins when DUSD(IA\&I) asks the military Services ${ }^{47}$ and Defense Agencies to identify areas where the parties are currently competing, are likely to compete in the future, and areas that pose vertical integration issues or organizational conflicts of interest. A small staff composed of representatives from DUSD(IA\&I) and the General Counsel gather additional information from the Services,

45 Defense Science Board, op. cit.

46 DoD adopted many of the Task Force recommendations in 1994 and formalized antitrust review policy in Impact of Mergers and Acquisitions of Major DoD Suppliers on DoD Programs, DoD Directive 5000.62, October 21, 1996. DUSD(IA\&I) leads the review for the USD(A\&T).

47 This report uses the familiar colloquial term "military Services" instead of the more accurate term, Military Departments, to refer to the Army, Navy, Marine Corps and Air Force acquisition activities. 
Defense Agencies, and the firms that are party to the transaction, where required. The Department of Defense uses this information gathering and analysis process to identify possible vertical integration problems.

The Department of Defense does not duplicate the actions of the antitrust agencies but focuses on understanding how the proposed transactions might affect cost, competition, innovation, and industrial capabilities in current and future DoD programs from a customer's perspective. Throughout the DoD and antitrust agency review process, the Department and antitrust agencies' staff share information and insight as appropriate, and work closely to identify and address issues on a timely basis.

DoD does not take a position in every case. The Deputy Secretary of Defense or USD(A\&T) typically decides on a final position to provide to the antitrust agencies on a given transaction.

\section{ANTITRUST REVIEWS OF DEFENSE INDUSTRY ARE SUCCESSFULLY ADDRESSING SOME LESS TRADITIONAL VERTICAL CONCERNS}

Assessing vertical integration in defense antitrust reviews poses several difficulties. In many industries, the largest number of investigations undertaken by the antitrust agencies relate to the horizontal aspects of mergers, and antitrust guidance and history reflect the horizontal focus. Economic theory suggests that some vertical integration may be beneficial, and the harms of vertical integration are more indirect and may take longer to appear. Additionally, the nature of the current vertical integration among defense firms varies from that witnessed in some other industries. In short, there are fewer models for the antitrust agencies and DoD to look to in identifying likely harms arising from a particular type of vertical defense transaction, and less precedent with remedies used in the past.

The antitrust agencies use the 1992 Horizontal Merger Guidelines in examining horizontal mergers, but they still use the 1984 Merger Guidelines to assess non-horizontal mergers (mergers that are vertical or not horizontal in nature). ${ }^{48}$ The 1984 Merger Guidelines describe two general categories of potential problems with vertical mergers:

- Increased barriers to entry.

- Facilitating collusion in the upstream market.

48 Defense Science Board, op. cit., describes the 1992 Horizontal Merger Guidelines in detail. Both the 1992 Horizontal Merger Guidelines and the 1984 Merger Guidelines may be obtained from the antitrust agencies. 
The antitrust agencies assess vertical foreclosure, which has been a potential concern in some defense cases, as a form of increased barrier to market entry. ${ }^{49}$

The Task Force identified thirty-four notable defense mergers and acquisitions that were consummated from 1994 through March 1997. In about twenty of these cases, the Department of Defense supported the antitrust agency in their reviews. ${ }^{50}$ Vertical concerns were the basis for antitrust agency consent orders in seven of these transactions, a significant occurrence. $^{51}$

Appendix D outlines the details of vertical integration concerns found, and remedies used, by the antitrust agencies in defense mergers and acquisitions during this time period. The remedies ordered by the antitrust agencies appear to be effective; no evidence, either from the antitrust agency's follow-ups, or the Department's ongoing interactions with firms, suggests otherwise. ${ }^{52}$

Based on the Task Force's review, the antitrust agencies and DoD appear to be capably and effectively identifying and addressing vertical concerns arising in defense transactions. The antitrust agencies and DoD processes appear to be flexible and adaptive. This is true in their success both in applying the 1984 Merger Guidelines to defense settings, and in determining remedies that might allow proposed transactions to proceed while remedying the particular concern as specifically as possible. Both the antitrust agency and DoD processes are more extensively investigating particular product lines of potential vertical concern where warranted, rather than blindly requiring the same level of detail for every product line assessed.

Potential for compromise of proprietary information, which has been a vertical concern in many defense mergers and acquisitions to date, is not explicitly addressed in the 1984 Merger Guidelines.

50

The number of cases (thirty-four) is a count of notable cases and does not represent all transactions that were proposed or consummated or the number of cases examined by antitrust agencies. Appendix D, "Defense Industry Antitrust Reviews," lists the thirty-four cases and the transaction values.

Some transactions that are not strictly vertical pose concerns similar to vertical cases. For example, concern can arise when a firm provides system requirements or design definition or other critical DoD-advisory services, and is acquiring, or being acquired by, a firm that would carry out the defined design or development activities. This presents an organizational conflict of interest. Prior to Litton's acquisition of PRC, PRC performed oversight of a Navy ship program in which Litton and General Dynamics were primes. The Department of Defense and FTC were concerned that if the buy proceeded, PRC could no longer provide objective oversight for the Navy. The FTC required PRC to divest the Navy contract as a condition of the acquisition.

52 FTC is currently performing a study to verify the effectiveness of firewalls. 
Finally, the reviews have dealt with many sizable transactions without issuing a Request for Additional Information, allowing the transactions to be quickly consummated and without firms' incurring the significant costs that such second requests entail. ${ }^{53}$

\section{B. DoD's acquisition processes provide little visibility into supplier products and technologies}

DoD managers may have difficulty identifying evidence of a growing vertical integration concern, particularly in more subtle forms.

To understand how the DoD, primes, and suppliers interact, the Task Force interviewed managers in several product areas in different life cycle phases. The Task Force also received presentations on how some firms select and manage their suppliers. Table 4 displays programs for which DoD provided data or presentations to the Task Force.

\section{DOD ACQUISITION MANAGERS HAVE LESS INTERACTION WITH SUPPLIERS}

Some changes in the Department of Defense's acquisition processes will, over time, make it more difficult for the Department to have independent insight or influence over suppliers' capabilities.

The Department's acquisition reform has institutionalized the philosophy that DoD should define performance requirements in contracts and hold the prime contractor responsible to deliver all aspects of the desired weapon system performance. This philosophy had developed to some extent before the latest reforms because experience indicates it allows the Department and prime contractors to draw clearer boundaries of risk, responsibility, and cost. In new contract awards, the Department of Defense is aggressively eliminating many of the mechanisms it formerly used to specify product details and industry processes and to keep "check" over its prime contractors̄. Many of these product specification and "checking" mechanisms were often judged to be burdensome, costly, and of questionable effectiveness.

In new weapon system acquisitions, the Department is increasingly defining "bottom line" measures of what primes must deliver and interacting with primes only in higher risk areas. This new approach has several implications for suppliers, as it means the Department lets the

53 See Appendix D, "Defense Industry Antitrust Reviews," for a list of cases from 1994 to the present that have been allowed to proceed without a Request for Additional Information. 
prime decide who will meet the program requirements, without DoD interference or approval of firms' supplier decisions. DoD acquisition managers seek limited information about their primes' first-tier suppliers, and are only involved with second- or lower-tier supplier matters if a problem threatens performance or delivery.

While it has long operated this way conceptually, the Department of Defense has historically been more involved in dealing with suppliers with below the prime in several ways by:

- Reviewing prime contractor's "make or buy" plans and decisions. The Department occasionally intervened in these decisions.

- Defining many critical subsystems or other items as government-furnished equipment (GFE), purchasing them separately, and providing them to the prime. In these areas, $\mathrm{DoD}$ often directly funded much of the suppliers' research and development work.

- Influencing supplier choices by defining detailed specifications.

- Working with the prime in reviewing suppliers' activities in most important program areas; more routinely visiting supplier facilities and overseeing their progress.

The Department of Defense is also defining its weapon system buys differently, packaging pieces once bought separately into a single contract. Today it often requires the prime to be responsible for a more comprehensive weapon system mission package-to procure and integrate every system and subsystem across multiple mission elements (for example, air and ground elements). The Department often tasks prime contractors to provide management and logistics support in later phases of the weapon system life.

In focusing its interaction fully on the prime contractor and standing back to let the primes manage broad areas, the Department is reshaping business opportunities in an industry already reordering itself by its increasing concentration. A few diverse primes have extensive resources and capability and are posturing themselves to be the leader in offering comprehensive "soup to nuts" management in their market areas. Firms with "systems of systems" capabilities, that is, with product lines in many interrelated systems areas (for example, satellites, space launch, ground communication links, etc.) have the advantage in meeting Department's comprehensive purchasing approaches. Suppliers' investment focus and capabilities are increasingly driven by the dynamics of their relationships to these few prime contractors. Firms who have traditionally contracted directly with the Department of Defense in some specialty subtier areas now rely on primes for a partnership or other entree into new systems. The Department and suppliers below the prime contractor increasingly do not interact. 
In parallel with acquisition practice changes, the Department of Defense is reducing the number of personnel assigned to all forms of management of its prime contractors, from weapon system program office technical staffs to DoD contract administrators at companies' facilities. Program offices could never have specialists for every important supplier area; with today's much smaller staffs, they can only manage priority areas. The Department is not maintaining records of supplier costs and capabilities, but relies on prime contractors for such insight. To some extent, reductions in DoD acquisition. personnel have necessitated acquisition changes. However, reform measures that emphasize relying on the primes have also made manning reductions possible and workable.

Appendix F highlights details of some of the ways that acquisition process changes and reduced manning affect the Department and supplier interactions.

Table 4. Programs Reviewed for Supplier Oversight and Vertical Integration

\begin{tabular}{|c|c|c|c|c|c|}
\hline Phase & Technology & \multicolumn{2}{|c|}{ New Products } & \multicolumn{2}{|c|}{ Mature Products } \\
\hline Activity & Science & Research & Development & \multicolumn{2}{|c|}{ Production/Upgrade } \\
\hline \multirow[t]{5}{*}{ Program } & \multicolumn{2}{|c|}{ IR\&D invesments } & & \multicolumn{2}{|r|}{ Aegis } \\
\hline & DoD S\&T & Joint Strike & & & \\
\hline & i & & SN & & Tanks \\
\hline & 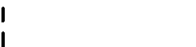 & & $\mathrm{F}-22$ & F-18* & \\
\hline & I & & & & Subs Nuclear Parts \\
\hline
\end{tabular}

INDIVIDUAL DOD ACQUISITION MANAGERS DO NOT HAVE INDUSTRY-WIDE VISIBILITY

DoD managers may need better industry-related skills to deal effectively at "arms length" with industry in acquisition programs.

At any point in time, DoD managers in different organizations are buying similar products and drawing on similar industrial capabilities; each manager often has limited insight into the other's requirements or decisions. Individual DoD acquisition managers are typically not in a position to have visibility, make judgments, or act with a DoD-wide perspective regarding primes or suppliers. Their responsibility and authority entail interacting with the industry to manage their own programs as best they can. DoD program managers have more cross-cutting industry insight if they are the only buyer for a product (for example, the Army Program Executive Officer for Land Systems, who buys all tracked combat vehicles), but this is the case in only a few areas. Also, program managers in product areas where the 
Department has traditionally had more interaction in product design or manufacture, or where the Department managed many GFE systems-such as submarines, tanks, jet engines, or munitions-appear better informed about suppliers.

Still, these managers' knowledge may be limited to the suppliers involved in their programs. For example, they may not know to what degree their supplier product capabilities are similar to commercial firms or products, to foreign defense firms' capabilities, etc., or what share of the overall market their buying represents for a given supplier. They may also fall into a "captive customer" mentality, that is, they may fully rely on their suppliers and be motivated to preserve the status quo. This does not promote a fully objective perspective.

Program managers have no responsibility or systematic mechanism to share their knowledge of suppliers with other DoD program or technology managers. Some knowledge is passed by experienced personnel rotating into new jobs, and by seminars, conferences, and other opportunistic means.

Having several DoD managers buy from the same market (in some cases today, a small market) poses some problems for the Department of Defense, particularly when the product market is defense-unique. DoD managers usually cannot act with the Department's full market power because they do not have its full market knowledge or authority. To some degree these problems can be ameliorated by education and experience. DoD program personnel need a solid base of industry knowledge and savvy to be smart buyers in today's changed industry environment and with new DoD acquisition approaches. DoD managers may find themselves with fewer bidders, and they may have to consider less traditional methods to achieve competitive effects.

In implementing a "hands off" management style with contractors, these managers who are unaware or inexperienced with industry operations and incentives may have difficulty knowing how to place realistic demands on firms, or how and when to make course corrections. However, current mandatory DoD acquisition career field training and credentials do not emphasize knowledge of product markets, industrial capabilities, or firms' business practices and economic incentives. DoD training and credentials typically emphasize knowledge of specialized DoD rules and processes. Since the Department has no way to fully coordinate individual program decisions that affect the same markets, and individual program personnel may not have enough training or experience to provide a framework for their interaction with industry, DoD managers may not be able to see vertical integration problems that emerge. 
DOD HEADQUARTERS STAFFS CREATE POLICY AND SOLVE PROBLEMS-THEY DO NOT MONITOR INDUSTRY

Effects of vertical integration may emerge over time and identifying them may require careful scrutiny of prime and subtier capabilities in particular product markets. DoD-wide and Service-wide oversight of industry product and technology capability is generally performed at the Office of the Secretary of Defense or Service Headquarters level staffs. Today these organizations provide policy and guidance, and deal with problems that arise. Without a more active, ongoing monitoring of selected product or technology areas at a DoD-wide level, the Department may not be able to recognize emerging vertical integration concerns. The Department of Defense does not have good mechanisms to share its industry knowledge across DoD in important supplier areas to help compensate for the limited insight being gained in individual weapon system acquisition programs.

Since 1993, DoD created several new mechanisms to elevate DoD's internal attention to industry matters:

- The Department created the Industrial Base Executive Committee, chaired by USD(A\&T), and with all Service Acquisition Executives and principal staff elements of the USD(A\&T) as members. This Committee is chartered to address defense industry areas of interest and concern, and meets on an as-needed basis.

- The Department implemented an orderly and coordinated process to review mergers and acquisitions, described earlier in this Section, operated by the DUSD(IA\&I).

- The Department created the position DUSD(IA\&I) with a charter and the stature to address DoD-wide industry matters. This organization actively assesses industrial capabilities, with extensive support of the military Services and industry. The resulting studies may be prompted by internal managers' concerns, or external concerns, such as a user or industry group expressing concern, or a firm announcing its intention to exit the market. For example, in 1995, DUSD(IA\&I) led studies of several major product sectors: helicopters, combat-tracked vehicles, torpedoes, space launch vehicles, and bombers. These broad studies characterized and assessed overall industry health, and identified future DoD spending in the area. These sector studies took a limited look at critical supplier areas below prime. More recent studies have increasingly focused on supplier level areas of potential concern: aerospace grade rayon, radiation-hardened integrated circuits, and microwave tubes.

The military Services and Defense Agencies that acquire defense products have organizations with missions to provide Service- or Agency-wide industry knowledge and insight, generally 
at the Headquarters level staff. In some cases (for example, Navy sea programs), industrial organizations are active in monitoring industry and providing program input. In other cases, the organizations only become involved when a problem arises that needs to be coordinated across their field activities. They are not typically chartered or staffed to provide supplier knowledge.

\section{DoD science and technology oversight}

Whether a prime or supplier is likely to become competitive in a new technology is, in part, based on receiving DoD science and technology (S\&T) funding. Because of the significant DoD budget reduction and resulting industry concentration, this reliance on DoD resources may be increasingly true for suppliers, particularly medium or smaller sized firms. However, the Department of Defense does not systematically assess the effects of its S\&T investments on supplier competitiveness or innovation, or the extent of firms' technology capabilities. Effects of vertical integration that may emerge subtly through technology development may be difficult for the Department to recognize.

The Department of Defense generally tries to take a free market approach to S\&T investment. It selects areas for S\&T investment based on meeting DoD's future needs, pursuing promising technologies, and fueling basic science for future technologies. DoD buys S\&T work by competing to the best available sources (universities, federal labs, and industry) and fostering industry or industry-government consortia.

Individual project managers across the military Services and Defense Agencies manage the Department's S\&T investment projects. The Director, Defense Research and Engineering (DDR\&E) performs DoD-wide oversight, but this is on a broad level. Technology investments are coordinated DoD-wide by Service-lead groups and by some DDR\&E-lead focus groups. ${ }^{54}$ However, they coordinate technical work, not industry matters. For example, there is a working group to coordinate technical focus of Service managers who make materials-related $\mathrm{S} \& \mathrm{~T}$ investments.

DoD does not cohesively manage technology across its development and application phases. For example, S\&T development projects and technology demonstrations are often managed by different groups. Individual DoD S\&T project managers cannot be responsible to track how or where a technology development progresses into a real defense system; "real

54 Military Services have a concept called "project reliance" by which they coordinate the technical focus of their S\&T activities. 
systems" happen over a long time and as a result of many different pieces of work. DoD expects firms to select, invest, and take risks to incorporate promising technologies into their defense products. When DoD invests science and technology dollars in a firm in a certain technology area, that firm must invest independently, or garner DoD later-phase development funds, or they may not become competitive in turning that technology into products.

In presentations to the Task Force, some firms expressed concern that large, vertically integrated primes could have an advantage over smaller or less vertically integrated firms in developing new subsystem or component technology because of the primes' larger IR\&D resource potential. ${ }^{55}$ The Department of Defense does not systematically track how suppliers' IR\&D investments relate to the Department's S\&T investments, although individual DoD S\&T project managers may monitor firms' investments in their assigned areas.

\section{CONCLUSION}

Because the Task Force found that vertical integration may pose concerns in the future, they considered how well the Department of Defense's current processes might recognize and address any such concerns. The Department affects vertical integration in two ways: in its participation in antitrust reviews of proposed industry mergers and acquisitions, and in its ongoing management of $\mathrm{DoD}$ acquisition programs.

- Regarding the antitrust review process, the Task Force found the DoD has been working very effectively with the antitrust agencies to identify and remedy vertical concerns raised by proposed transactions. The Task Force has no recommendations for change in DoD's review process.

- In acquisition programs, the Task Force believes DoD managers may have difficulty recognizing emerging problems posed by vertical integration. DoD has significantly changed its buying practices since 1993. DoD is asking prime contractors to bid to more comprehensive packages of mission and logistics requirements, and program managers are removing themselves from detailed

55 DoD provided data to the Task force showing that, in 1995, firms' investment in IR\&D was $\$ 2$ billion, representing almost $25 \%$ of DoD S\&T (6.1-6.3) funding. While the absolute IR\&D funding level has declined since the 1980 s, both prime and major subtier suppliers' IR\&D as a percentage of sales has held fairly stable (about 2\%). (Firms' IR\&D/sales (percentage) was calculated from data collected by Defense Contract Audit Agency.) Laws governing IR\&D do not allow DoD to require firms to share project technical information with DoD. However, most firms report their project information voluntarily into a DoD-run voluntary database (proprietary). 
oversight of their prime contractor's day to day operations. These reforms are changing the dynamics between DoD managers, defense primes, and suppliers. DoD program personnel have increasingly less interaction with suppliers or products below the prime level. This compounds the fact that they are often unable to see the effects of their individual program decisions on the broader industrial capabilities.

The Task Force proposes five recommendations to help DoD identify and address concerns that may arise due to increased vertical integration: Details are provided in the Summary and Recommendations Section.

1. Expand the Department's monitoring of vertical supply relationships for selected, important defense products and technologies.

2. Focus DoD acquisition and technology strategies and investments to support competition and innovation.

3. During antitrust reviews, continue to scrutinize carefully the potential harms from vertical integration.

4. Strengthen business- and industry-related skills of DoD's acquisition personnel.

5. Develop measures that help DoD managers to recognize areas of potential vertical integration concern and trigger more detailed investigation. 
APPENDICES 


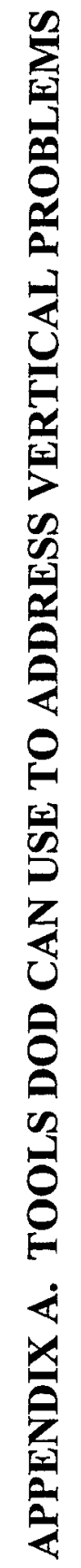




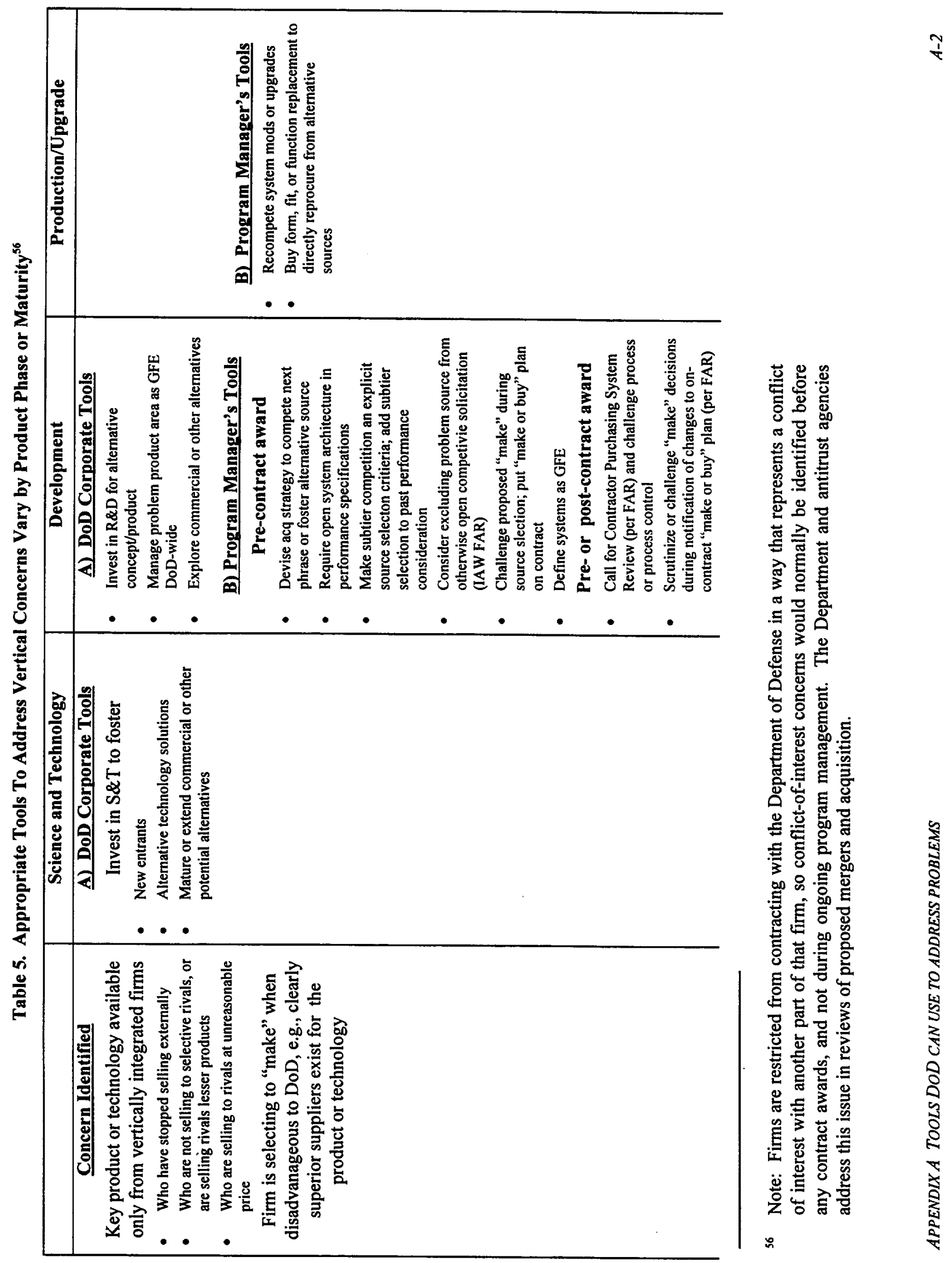




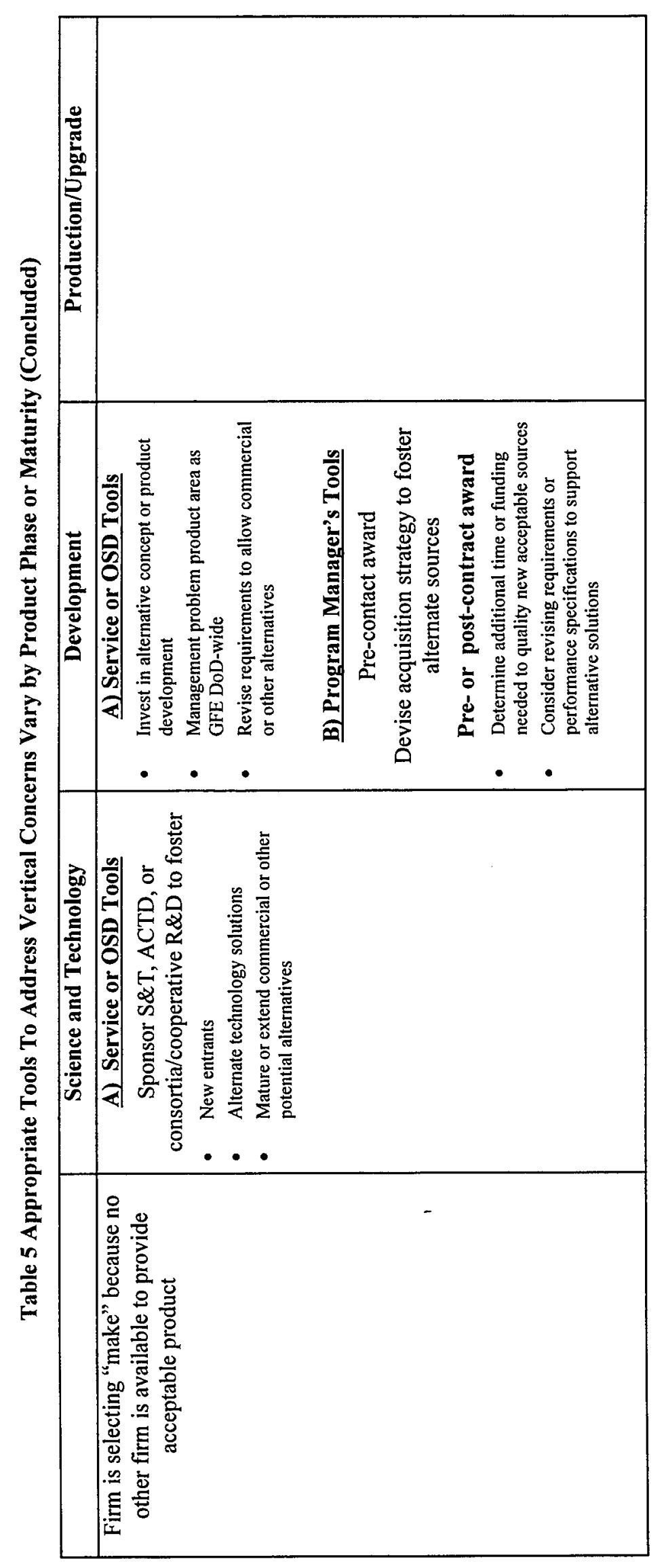

$\eta$ 



\section{APPENDIX B. TASK FORCE CHARTER, MEMBERSHIP, MEETINGS, AND BRIEFING TOPICS}

\section{Charter}

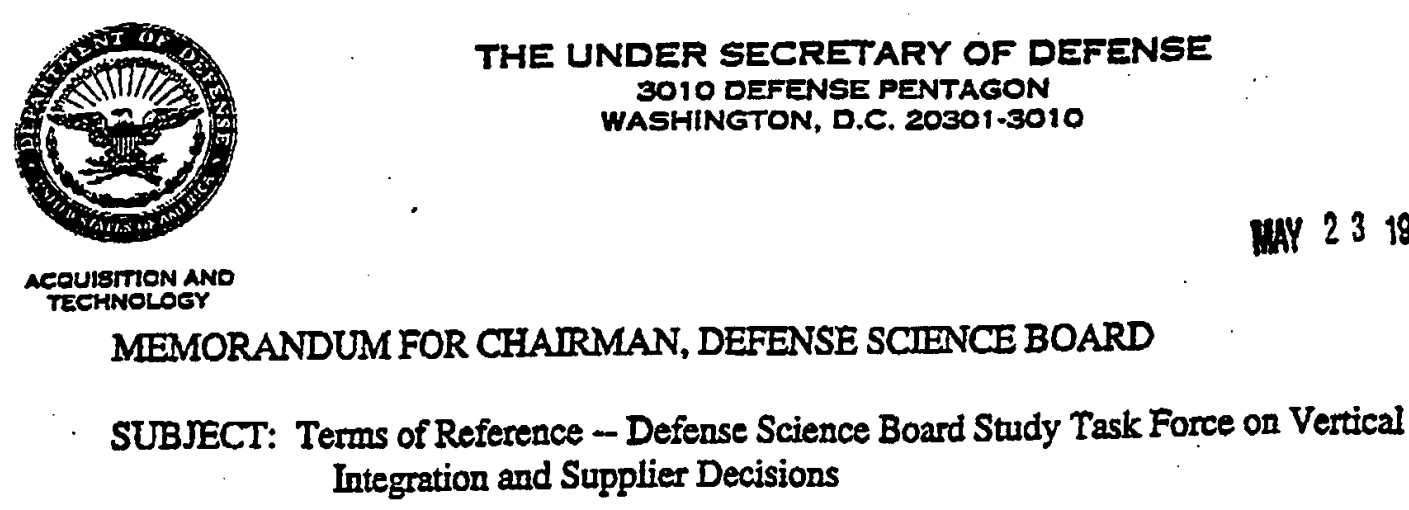

As a result of ongoing defense industry downsizing, defense industrial capabilities are being concentrated in fewer firms. This consolidation is generally beneficial for the Department because it reduces excess capacity and thereby lowers costs. However, the Deparment must ensure that any increase in vertical integration and industrial concentration, and the associated corporate supplier decisions, do not negatively affect DoD programs.

I request that you establish a Defense Science Board Task Force to examine the effects of defense industry vertical inegration and supplier decisions and make recommendations on what, if any, revisions to DoD policy, practice, or investment strategies are required to deal with these issues. The Task Force should consider:

- Metrics for assessing the degree of vertical integration: (1) in the defense industry over time, and (2) in comparison with other industries.

- The effects of vertical integration and likely corporate supplier decisions on price and technical competition for DoD programs, and on technical innovation for future defense products.

- Indicators DoD should use in monitoring areas of potential concern (including competitive technical activities, pricing, or make-or-buy practices).

- The extent to which new DoD acquisition approaches, particularly the increased use of commercial suppliers, commercial products, and open systems architectures, will ameliorate any identified supplier entry concerns.

The Deputy Under Secretary of Defense (Industrial Affairs and Instailations) will sponsor the Task Force. Mr. William G. Howard will serve as the Task Force Chairnan. Christine Fisher will serve as the Executive Secretary, and LTC T. Van Horn as the Defense Science Board Secretariat Representative. The Task Force should begin its work as soon as possible and provide $a$ final report by December 31, 1996.

This Task Force will be operated in accordance with the provisions of P.L. 92-463, the "Federal Advisory Committee Act," and DoD Directive 5104.5, the "DoD Federal Advisory Committee Management Program." It is not anticipated that this Task Force will need to go into 
any "particular matters" within the meaning of Section 208 of Title 18, U. S. Code, nor will it cause any member to be placed in the position of acting as a procurement official.

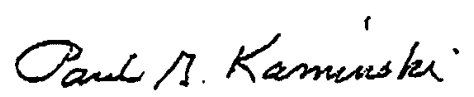

Paul G. Kaminski 


\title{
Defense Science Board Task Force on Vertical Integration and Supplier Decisions
}

\author{
Membership Roster \\ John Goodman \\ Deputy Under Secretary of Defense (Industrial Affairs and Installations) \\ Sponsor \\ Christine Fisher, OUSD(A\&T) IA\&I \\ Executive Secretary
}

Dr. William G. Howard, Consultant

Chairman

\section{Task Force Members}

Mr. Thomas Corcoran, Lockheed Martin

Mr. Robert E. Litan, Brookings Institution

Ms. Janet McDavid, Hogan \& Hartson LLP

Mr. James Skaggs, Tracor, Inc.

Mr. Dennis H. Trosch, (DoD Counsel, Ret.)
Dr. Carol Evans, Georgetown University Mr. Hank McCard, Textron, Inc. Mr. James Sinnett, McDonnell Douglas Mr. John Stewart, McKinsey \& Co., Inc. Mr. Gordon Williams, (TRW, Ret.)

\section{Government Advisors}

Mr. Whit Peters, DoD PrinDep, Gen Counsel

Mr. Larry Fullerton, Department of Justice
Ms. Ann Malester, Federal Trade

Commission

Mr. Fred Reinhard, USD(A\&T)/DPP

\section{Government Support}

Dr. William Pegram, OUSD(A\&T) IA\&I

Robert Read, OUSD(A\&T) IA\&I

William Brykczynski, Sarah Nash, Katydean Price, Dr. Robert Rolfe, and Herbert Brown, Institute for Defense Analyses

LTC T. Van Horn, DSB Secretariat

\section{Support}

Mr. Hilton Hanson, SAIC 


\section{Meeting Dates and Briefings}

September 4, 1996

Task Force Charter

Dr. John Goodman, Deputy Under Secretary of Defense (Industrial Affairs and Installations)

September 19, 1996

Standards of Conduct Briefing

Steve Epstein, Office of the General Counsel/ Standards of Conduct Office

Task Force Sponsor's Perspective

John Goodman, Deputy Under Secretary of Defense (Industrial Affairs and Installations)

\section{Background: Industry Structure and Economics}

Defense Industry Structure

Jerry Lundquist, McKinsey \& Co., Inc.

Economic Theories of Vertical Integration

Dr. Bill Pegram, Department of Defense (with input of Dr. C. Shapiro, USC Berkeley)

\section{Mergers and Acquisitions}

Antitrust Review Process

Ann Malester, Federal Trade Commission

DoD Merger and Acquisition Review Process

CAPT Zack Wilhoit, Department of Defense

Effects of Acquisition Reform on Industry Structure

Dr. Jacques Gansler, TASC

September 20, 1996

Non-Horizontal Concerns and Defense Examples

Ann Malester, Federal Trade Commission

Non-Horizontal Antitrust in Other Markets (Media, Telecommunications)

Jim Wade, Department of Justice 
Assessing Innovation Markets

Janet McDavid, Hogan and Hartson

Health of the Defense Industry-Primes and Suppliers

Pierre Chao, Morgan Stanley

October 30, 1996

\section{Defense Industry Consolidation: Strategies and Effects}

Evolving Structure of Defense Industry (United States and Foreign)

Michael Urfier, Bear Stearns

October 30, 1996

\section{Effects of Consolidation: A Series of Questions}

\section{Prime Views}

Statement of Dr. Vance D. Coffman,

Vance D. Coffman, President and Chief Operating Officer, Lockheed Martin

Vertical Integration: A Discussion,

John Weaver, President and Chief Operating Officer, Hughes Aircraft Company

Vertical Integration: One Prime Contractor's Perspective,

James Sinnett, Corporate Vice President for Technology, McDonnell Douglas

\section{Supplier Views}

Vertical Integration in the Defense Industry: A Supplier's View

Michael Brown, President and Chief Operating Officer, Litton Industries

Impact of Vertical Integration in the Defense Industry

Bob Carrier, Program Manager for Strategic Planning, Harris Corporation, Electronic Systems

Vertical Integration and Supplier Decisions: A Supplier's Perception

John Rutledge, Director, Program Management, ESCO

\section{Industry Supplier Management}

General Dynamics Land Systems

Charlie Hall, Vice President for Domestic Operations, General Dynamics Land Systems

Lean Aircraft Study: Supplier Relations Findings

Kirk Bozdogan, Massachusetts Institute of Technology 
October 31,1996

\section{DoD Supplier Management}

DoD Role in "Make or Buy"

Fred Reinhard, Deputy Director, Defense System Procurement Strategies Contractor Purchasing Systems

Defense Contract Management Command Actions

Ron O'Daniell, Defense Contract Management Command

F-22 SPO Perspective

Brig Gen Michael Mushala, USAF, System Program Director

Aegis Destroyer Perspective

CAPT Duane Covert, USN, PEO Surface Combatants/Director, Systems Acquisition

New Attack Submarine Electronics

CAPT Glenn Sieve, PEO Submarine, Program Manage

November 18, 1996

\section{Assessing Suppliers' Technology Capabilities}

Transitioning Innovation into System Design

Hon. Dr. Anita Jones, Director, Director, Defense Research and Engineering

Trends in Defense Technology Investment: An Industry Perspective

Hank McCard, Senior Vice President of Operations, Textron, Inc

James Skaggs, CEO, TRACOR, Inc.

Measures of Industry Independent Research and Development

Bill Brykczynski, Institute for Defense Analyses

November 19, 1996

Measuring Effects of Specification and Standards Reform

Walter Bergmann, Director, Acquisition Practices, ODUSD (Industrial Affairs and Installations)

Effects of Sole Source Suppliers: A Case Study

Lou Gagne, President, Marine Mechanical

David Pye, Director, Reactor Engineering, US Navy

December 16, 1996 
Industry Strategic Alliances

Dr. Carol Evans, Georgetown University

International Defense Market and Industry

Dr. Gerald Abbott, Industrial College of the Armed Forces

Open System Architecture and the DoD

Honorable Noel Longuemare, PDUSD(A\&T)

December 17, 1996

Industry Perspectives on Consolidation

Durrell Hillis, Senior Vice President and General Manager, Motorola

\section{Motivating Industry Change}

Single Process Initiative

Marialane Schultz, DCMC

Alternative Competition Strategies

Dr. Jacques Gansler and Lou Kratz, TASC, Inc.

Fred Reinhard, Deputy Director, Defense Procurement

January 14,1997

Members' working session (no briefings presented) 


\section{APPENDIX C. GLOSSARY}

CIP

$\mathrm{CNI}$

DCAA

DSMC

DDR\&E

DUSD(IA\&I)

EMD

FAR

GD

GFE

GPVI

HSR

ICAF

IBEC

IPT

IR\&D

JASSM

JSF

OSD

OIPT

PDRR

SETA

USD(A\&T)
Common Integrated Processor

Communication/Navigation Identification

Defense Contracts Administration Agency

Defense Systems Management College (Industrial College of the Armed Forces)

Director, Defense Research and Engineering

Deputy Under Secretary of Defense (Industrial Affairs and Installations)

Engineering and Manufacturing Development

Federal Acquisition Regulations

General Dynamics Corporation

Government-Furnished Equipment

Graphics Processor Video Interface

Hart-Scott-Rodino

Industrial College of the Armed Forces

Industrial Base Executive Committee

Integrated Product Team

Independent Research and Development

Joint Air-to-Surface Standoff Missile

Joint Strike Fighter

Office of the Secretary of Defense

Over-arching Integrated Product Team

Program Definition and Risk Reduction

Systems Engineering Technical Assistance

Under Secretary of Defense for Acquisition and Technology 


\section{APPENDIX D. DEFENSE INDUSTRY ANTITRUST REVIEWS}

\section{FTC/DOJ antitrust review process}

- The agency review typically begins with the firms' Hart-Scott-Rodino (HSR) filing with the Federal Trade Commission and the Antitrust Division of the Department of Justice. During the thirty days following the filing, the two agencies review the filing to determine if either wishes to investigate further. They may choose to consult with the Department of Defense at this time. If both agencies express an interest, the agencies decide which agency will conduct the review.

- The designated agency will typically begin contacting the merging parties, customers, and competitors to better understand the industry and the effect of the transaction. Within thirty days of the firms' filing, the agency must decide whether to let the transaction be consummated or to issue a Request for Additional Information (termed a "second request"). If the agency issues a second request, the parties must comply with this second request before they can consummate the merger. These second requests typically ask for a great deal of information, and the parties often try to provide sufficient information to satisfy the concerns of the antitrust agencies. Once the parties comply with the second request, the antitrust agency generally has twenty days to decide whether to attempt to block the transaction unless the parties extend this period.

- The chart on the next page shows the antitrust review process flow and associated time periods. 


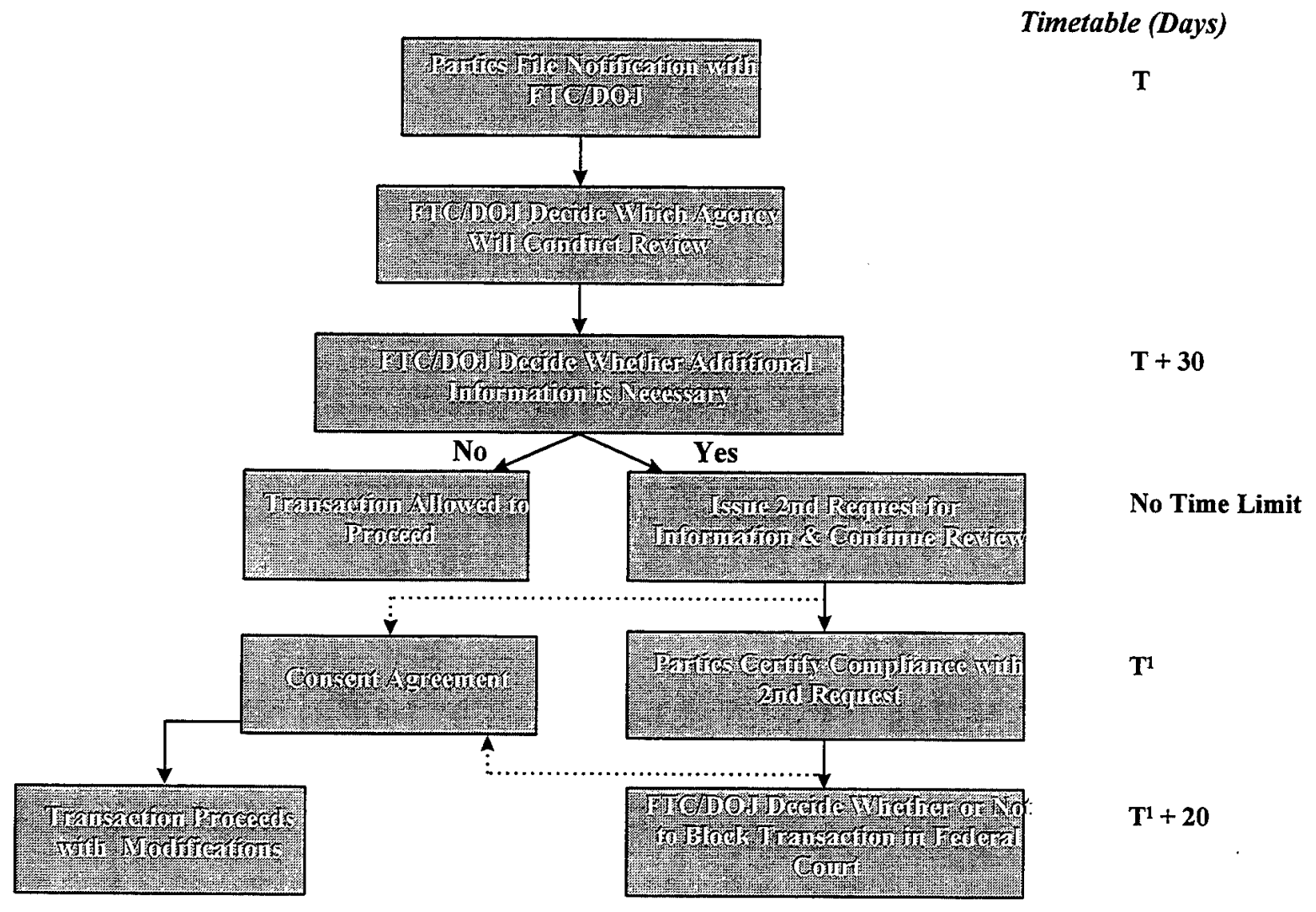

Table 6. Antitrust Review Process Flow and Associated Time Periods

\section{Mergers and Acquisitions: 1994-Present}

The Task Force identified thirty-four notable defense mergers and acquisitions consummated from 1994 through March 1997 (these do not represent all cases proposed or consummated during this period). Table Seven shows the thirty-four cases and identifies where there were remedies, where the antitrust agency review was completed within the initial thirty-day period, and where with no second request issued. Table Eight reflects the cases within this timeframe that resulted in antitrust agency remedies for vertical concerns, describes the nature of the concern, and the remedy ordered. The Task Force identified three more transactions underway in 1997. 
Table 7. Notable Merger and Acquisition Cases: March 1994-March 1997
Acquiror
Acquiree
Value
Agency
2d
Req
Cons.
Decree

\begin{tabular}{|c|c|c|c|c|c|c|}
\hline Loral & IBM Federal Systems & $\$ 1.575 \mathrm{~B}$ & FTC & & $3 / 1 / 94$ & \\
\hline Northrop & Grumman & $\$ 2.100 \mathrm{~B}$ & FTC & & $4 / 4 / 94$ & \\
\hline Martin Marietta & General Dynamics Space Systems & $\$ 209 \mathrm{M}$ & FTC & $\sqrt{ }$ & $5 / 2 / 94$ & $\sqrt{ }$ \\
\hline Westinghouse Elec Sys & Norden Systems & $<\$ 100 \mathrm{M}$ & $\overline{\mathrm{DOJ}}$ & $\sqrt{ }$ & $6 / 1 / 94$ & \\
\hline Northrop Grumman & Vought & $\$ 130 \mathrm{M}$ & FTC & & $7 / 31 / 94$ & \\
\hline Allied Signal & Textron Lycoming & $\sim \$ 375 \mathrm{M}$ & FTC & $\sqrt{ }$ & $10 / 28 / 94$ & \\
\hline Litton & Teledyne Electronic Systems & not avail. & FTC & & $12 / 30 / 94$ & \\
\hline Hughes & CAE Link & $\$ 170 \mathrm{M}$ & FTC & & $2 / 27 / 95$ & \\
\hline Alliant Techsystems & Hercules Aerospace & $\$ 466 \mathrm{M}$ & FTC & $\sqrt{ }$ & $3 / 15 / 95$ & $\sqrt{ }$ \\
\hline Lockheed* & Martin Marietta & $>\$ 9 B$ & FTC & $\sqrt{ }$ & $3 / 15 / 95$ & $\sqrt{ }$ \\
\hline Rolls Royce & Allison Gas Turbine & $\$ 525 \mathrm{M}$ & $\overline{\text { FTC }}$ & & $3 / 30 / 95$ & \\
\hline Tracor & Lundy Tech Center & $\$ 7 \mathrm{M}$ & FTC & & $3 / 31 / 95$ & \\
\hline Loral & Unisys Defense Operations & $\$ 862 \mathrm{M}$ & FTC & & $5 / 5 / 95$ & \\
\hline Litton & Imo & not avail. & FTC & $\sqrt{ }$ & $6 / 5 / 95$ & \\
\hline E-Systems* & Raytheon & $\$ 2.3 \mathrm{~B}$ & DOJ & & $6 / 15 / 95$ & \\
\hline General Dynamics & Bath Iron Works & $\$ 300 \mathrm{M}$ & FTC & & $9 / 17 / 95$ & \\
\hline GM Hughes & Magnavox Electronic Systems & $\$ 370 \mathrm{M}$ & $\overline{\mathrm{DOJ}}$ & $\sqrt{ }$ & $12 / 14 / 95$ & \\
\hline Litton & Hughes-Delco Inertial Systems & $\sim \$ 70 \mathrm{M}$ & FTC & & $12 / 31 / 95$ & \\
\hline Allied Signal & Northrop Grumman Precision & $\sim \$ 50 \mathrm{M}$ & FTC & $\sqrt{1}$ & $12 / 31 / 95$ & \\
\hline Logicon & Geodynamics & $\$ 32 \mathrm{M}$ & $\overline{\mathrm{DOJ}}$ & & $1 / 19 / 96$ & \\
\hline Litton & Sperry Marine & $\$ 160 \mathrm{M}$ & FTC & & $2 / 9 / 96$ & \\
\hline GM Hughes & Litton-Itek & $\$ 26 \mathrm{M}$ & $\overline{\text { FTC }}$ & $\sqrt{ }$ & $2 / 16 / 96$ & $\sqrt{ }$ \\
\hline Litton & PRC & $\$ 425 \mathrm{M}$ & FTC & $\sqrt{ }$ & $2 / 20 / 96$ & $\sqrt{ }$ \\
\hline Northrop Grumman & Westinghouse Electronic Systems & $\$ 3.6 \mathrm{~B}$ & $\overline{\mathrm{DOJ}}$ & & $3 / 2 / 96$ & \\
\hline General Dynamics & Teledyne Vehicle Systems & $\$ 55 \mathrm{M}$ & DOJ & & $3 / 29 / 96$ & \\
\hline Lockheed Martin & Loral & $\$ 9.5 \mathrm{~B}$ & FTC & $\sqrt{ }$ & $4 / 22 / 96$ & $\sqrt{1}$ \\
\hline Raytheon & Chrysler Technologies & $\$ 455 \mathrm{M}$ & FTC & $\sqrt{ }$ & $6 / 14 / 96$ & $\sqrt{1}$ \\
\hline Southwest Marine & Continental Maritime & not avail. & $\mathrm{DOJ}$ & & $6 / 14 / 96$ & \\
\hline GEC-Marconi & Hazeltine & $\$ 110 \mathrm{M}$ & $\begin{array}{c}\text { neither* } \\
*\end{array}$ & & $7 / 10 / 96$ & \\
\hline Tracor & Cordant & $\$ 65-80 \mathrm{M}$ & FTC & & $9 / 26 / 96$ & \\
\hline Boeing & Rockwell Aerospace \& Defense & $\$ 3.025 \mathrm{~B}$ & FTC & $\sqrt{ }$ & $12 / 6 / 96$ & $\checkmark$ \\
\hline Litton & SAIT Division of SAIC & not avail. & $\overline{\mathrm{DOJ}}$ & & $12 / 31 / 96$ & \\
\hline General Dynamics & $\begin{array}{c}\text { Lockheed Martin Armament \& } \\
\text { Defense Systems }\end{array}$ & $\$ 450 \mathrm{M}$ & $\overline{\mathrm{DOJ}}$ & & $1 / 1 / 97$ & \\
\hline
\end{tabular}




\begin{tabular}{|c|c|c|c|c|c|c}
\hline GM Hughes & $\begin{array}{c}\text { Alliant Techsystems Marine } \\
\text { Systems Group }\end{array}$ & $\$ 141 \mathrm{M}$ & FTC & & $2 / 28 / 97$ & \\
\hline & Announced/Under Review & & & & & \\
\hline Boeing* & McDonnell Douglas & $\$ 13.3 \mathrm{~B}$ & FTC & $\sqrt{ }$ & NA & \\
\hline Raytheon & $\begin{array}{c}\text { Texas Instruments Defense } \\
\text { Business }\end{array}$ & $\$ 2.95 \mathrm{~B}$ & DOJ & $\sqrt{ }$ & NA & \\
\hline $\begin{array}{l}\text { GM Hughes Defense } \\
\text { Business* }\end{array}$ & Raytheon & $\$ 9.5 \mathrm{~B}$ & DOJ & TBD & NA & \\
\hline
\end{tabular}

${ }^{*}$ For mergers, acquiring and acquired companies are shown in alphabetical order.

** In some cases, after reviewing the companies' filing, neither agency will undertake a substantive review, and the transaction is allowed to proceed. 


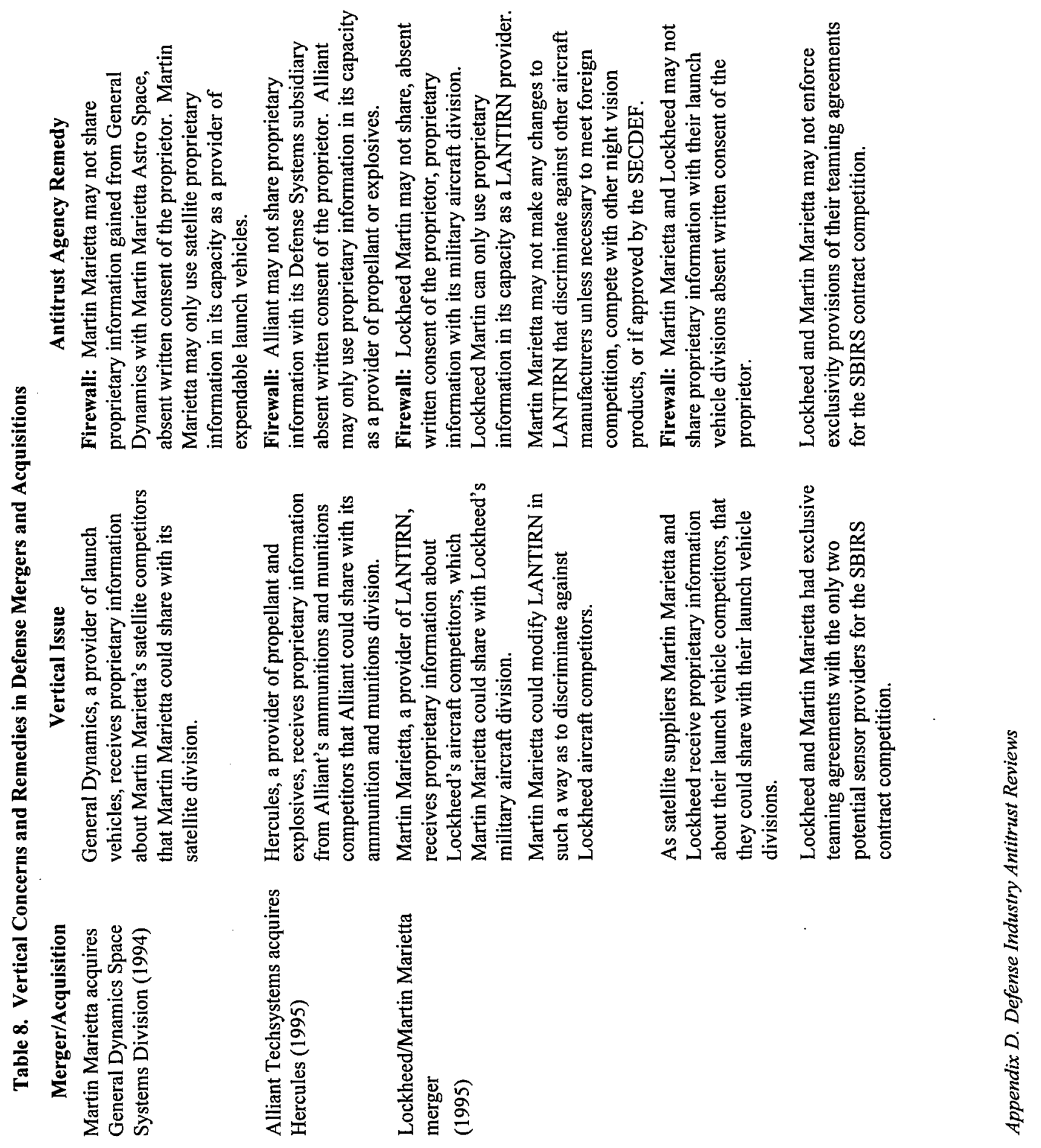



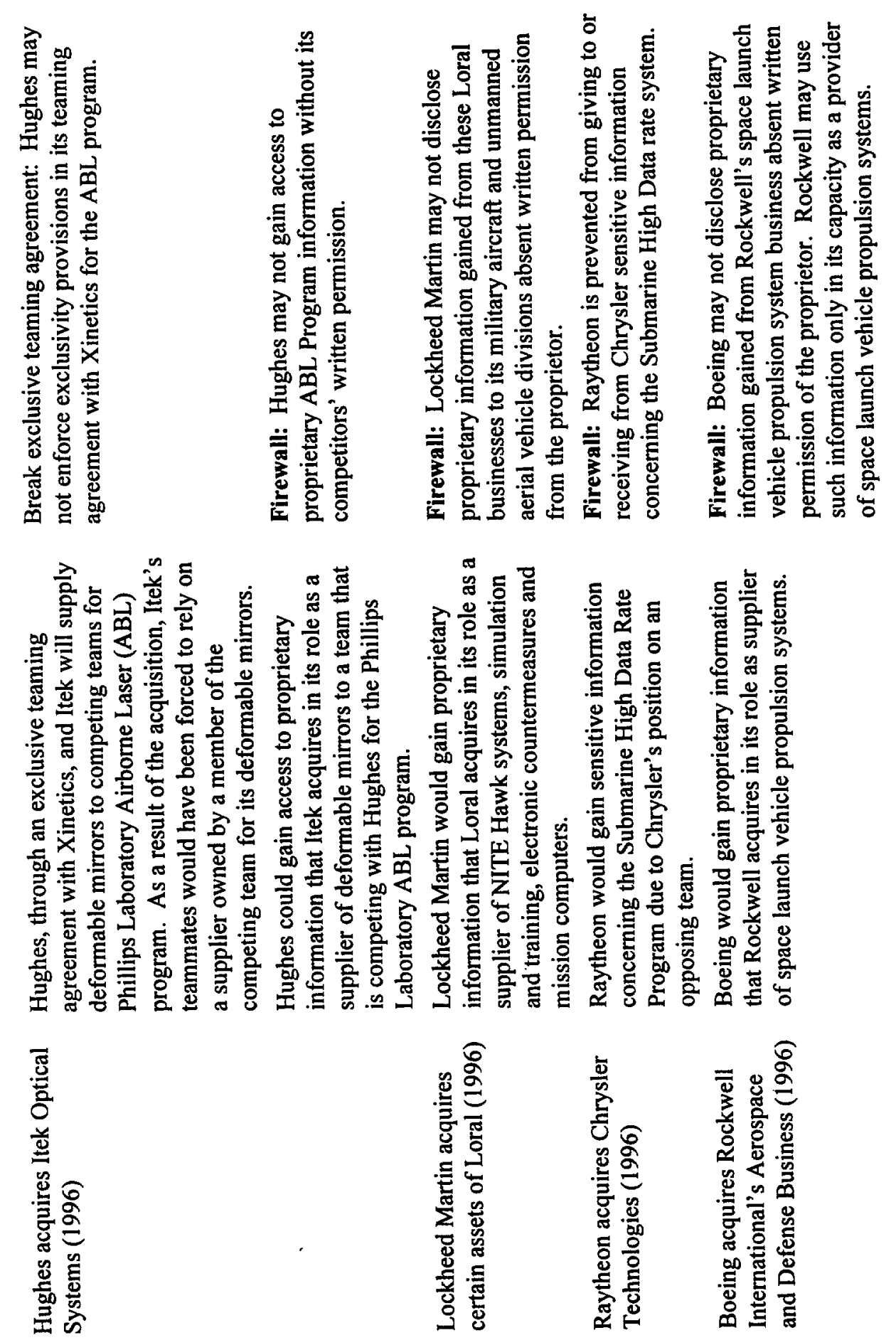


\section{APPENDIX E. PRIME CONTRACTORS' "MAKE" VALUE IN EXISTING DOD PROGRAMS}

Most DoD program offices do have some information on their prime contractors" "make" percentage of program value (the primes' fraction of the total program value). However, this data varies by program and is kept in the program office. DoD does not require anyone to routinely collect or compare such data across its programs. To find this data, the Task Force had to look to existing studies and to specifically request data from individual program offices.

Traditionally, primes have bought many subsystems and components from outside suppliers. One 1992 Logistics Management Institute (LMI) study found that prime "make" values varied by product area but averaged $57 \%$ of prime sales (see Table Nine). ${ }^{57}$ The values in Table Nine represent the prime contractors' internal portion of the product value (as a percentage of sales in that product area.) At that time, LMI found that the primes surveyed were not bringing work in-house at the expense of suppliers. In their survey, fourteen of thirty-four company divisions said they might bring work in-house, but this was rarely their preferred option.

Table 9. Average Defense Prime "Make" Values, 1991*

\begin{tabular}{|cc|}
\hline Defense Commodity Type & Prime Mark Value Sales \\
\hline Aircraft & $45 \%$ \\
Combat vehicles & $47 \%$ \\
Ships & $58 \%$ \\
Missiles & $60 \%$ \\
Electronics & $60 \%$ \\
\hline
\end{tabular}

*Average of all commodities of this type in the survey. Source: LMI, 1992

A separate LMI study performed in 1991 found the prime's internal "make" value to be even lower, averaging $40 \%$ of the product cost across different defense product types. Again, the

57 D. Peterson et al., Trends in Defense Industrial Base Capacity, LMI, June 1992. LMI surveyed 9 firms reporting on 34 divisions, working on more than 175 different defense programs, and representing $22 \%$ of the FY91 prime contract awards. 
percentage varied by product type: shipbuilders had the highest percentage, and aircraft primes had the lowest percentage of internal product cost. ${ }^{58}$

DoD program managers who made presentations to the Task Force observed that prime firms have not been reversing their "buy" decisions to increase their internal make value on current programs. The Task Force reviewed existing DoD data on primes' "make and buy" content in selected programs across different life cycle phases: the F-18 C/D and E/F, the F-22, and Joint Strike Fighter aircraft programs. The Task Force asked these selected DoD program offices to provide the data already available in their offices regarding prime contractors' "make" value. The Task Force also asked that no new data be collected from firms. While all programs contacted had some prime "make" value data, the level of detail available varied among different program offices.

In these programs, the data presented demonstrated that firms tend to maintain current supply sources once they are established on a program. There was little difference in primes' "make" percentage between firms with extensive new vertical capabilities and firms that had not acquired new vertical business units. Firms who had gained new vertical capabilities (due to mergers or acquisitions) during the course of their program did not notably change the type of products they are providing on the program, or their overall "make" percentage of program value.

\section{System Upgrade Program: F-18 C/D to F-18 E/F}

There are only modest changes in the prime's "make" content and in the major suppliers across these aircraft configurations and across time. ${ }^{59}$ McDonnell Douglas, the DoD prime, continued its partnership with Northrop Grumman (Northrop has about $40 \%$ of the total value) from the F-18 C/D to the E/F. McDonnell Douglas and Northrop Grumman's respective "make" ratios have grown only slightly between the two models (and the many years that passed between development of these two models). McDonnell Douglas did not have significant merger and acquisition activity in this period. Northrop did have significant additions by acquisition during this period, including the former Grumman and Westinghouse (see Table Ten.)

58 E. Gentsch and J. McInnis, A Profile of Defense Manufacturing Costs and Enabling Technologies, LMI, January 1992. This study was based on a survey of 32 different programs representing $39 \%$ of the DoD budget. Survey included 8 aviation, 10 missile, 2 ship, 1 combat vehicles, 6 ammunition, and 5 "other" programs.

s9 Approximately $90 \%$ (by cost) of the F-18E/F avionics will be common with the F/A-18C/D. The high commonality between the F-18 C/D and E/F aircraft, in part, drives supplier stability. McDonnell Douglas 
Table 10. F-18 Prime/Partner Make/Total Value

\begin{tabular}{|c|c|c|}
\hline \multicolumn{2}{|c|}{ McDonnell Douglas } & \multirow{2}{*}{$\begin{array}{c}\text { Northrop Grumman } \\
\text { (Major Partner, } \sim 40 \% \text { of Total) } \\
\text { Make value of partners' } 40 \%:\end{array}$} \\
\hline Make valu & naining $60 \%$ :* & \\
\hline $\mathrm{F}-18 \mathrm{C} / \mathrm{D}$ & $47 \%$ & $52 \%$ \\
\hline $\mathrm{F}-18 \mathrm{E} / \mathrm{F}$ & $52 \%$ & $58 \%$ \\
\hline
\end{tabular}

*Since McDonnell Douglas awards $40 \%$ of the overall value to partner Northrop, McDonnell's make value equates to $30 \%$ of the total aircraft value.

Source: F-18 Program Office. Note this data reflects the planned E/F configuration and the historical C/D configuration.

\section{Ongoing System Development Program: F-22}

The F-22 program, which is well into the Engineering and Manufacturing Development phase, has seen no major suppliers change within the last five to eight years.

- Long-term arrangements established by the primes during the earlier Demonstration and Validation phase were carried into the current program; no major supplier changes were made in the transition from Demonstration and Validation to this phase. This continuity is expected as they transition into production. The F-22 major subcontractors (major suppliers on contract to the prime), as depicted in Table Twelve, represent a diverse group of firms and a mix of external and internal sources.

- The prime contractors-Lockheed Martin for the aircraft and Pratt and Whitney for the engine-have had a stable "make" percentage throughout the EMD phase with one notable exception. The acquisition of General Dynamics Ft Worth Division by Lockheed changed the Lockheed share of the airframe development from $33 \%$ to $66 \%$, as Lockheed and GD were partners in the original contract bid. This reflect a more horizontal rather than vertical change in Lockheed's work share.

reports three major supplier changes and Northrop Grumman reports five. Component changes in subsystems are a result of increased capabilities (increased capacity hydraulics, enhanced generators, improved ECS/thermal management, etc.). The F-414 engine is the result of a development effort, but it was not a full development as it is a derivative of the earlier A-12 engine development. Of the suppliers, $96 \%$ were retained from the F-414 Engineering and Manufacturing Development (EMD) phase for the F-414 engine production. 
Table 11. F-22 Prime "Make"/Total Value

\begin{tabular}{cc|}
\hline Major Component Area & Lockheed "Make" Value/Tot Development \\
\hline Airframe & $66 \%$ (Prime: Lockheed Martin) \\
& (note 34\% Partner: Boeing) \\
Avionics and Flight Controls & $7 \%$ (Prime: Lockheed Martin) \\
Weapons & $33 \%$ (Prime: Lockheed Martin) \\
Propulsion & $30 \%$ (Prime: Pratt \& Whitney) \\
\hline
\end{tabular}

Source: F-22 Program Executive Office. Note this data reflects the Engineering and Manufacturing Development phase.

\section{New System Development Program: Joint Strike Fighter}

The Department of Defense awarded a contract for the first development phase of the Joint Strike Fighter in November $19966^{60}$ This program is funding two prime aircraft contractor competing development teams; at the end of this phase, one team will be selected to continue into a further development phase. (Note: The program is also directly contracting for propulsion work.) The DoD program office provided current prime internal "make" value data to the Task Force Chairman, but it cannot be included here as it is competition sensitive. For purposes of this study, the data were inconclusive at this time: the program is very new, primes are still defining the system, and they have not made final sourcing decisions in many areas.

The Joint Strike Fighter program is separately funding and contracting for several technology maturation projects (that is, contracts separate from the two prime development contracts). Table Thirteen lists the major Joint Strike Fighter contracts, including the technology maturation contracts and the firms performing the work. Several of these technology activities started in an earlier program phase and are continuing until completion in the next one to two years. Both prime aircraft contractors will have access to the technology products and concepts that emerge from these technology programs, and the primes can elect to incorporate the output as a part of the design they propose to the Department at the competition for the next phase. By awarding some technology programs separately from the prime development team contracts, the Joint Strike Fighter program office has encouraged competitive technology work to continue in the selected areas. At the same time, the program office is allowing the primes to select and be responsible for their own final team composition for the next phase.

60 The Department of Defense calls the current phase Program Definition and Risk Reduction (PDRR). 
Table 12. F-22 Prime Contractors and Major Subcontractors*

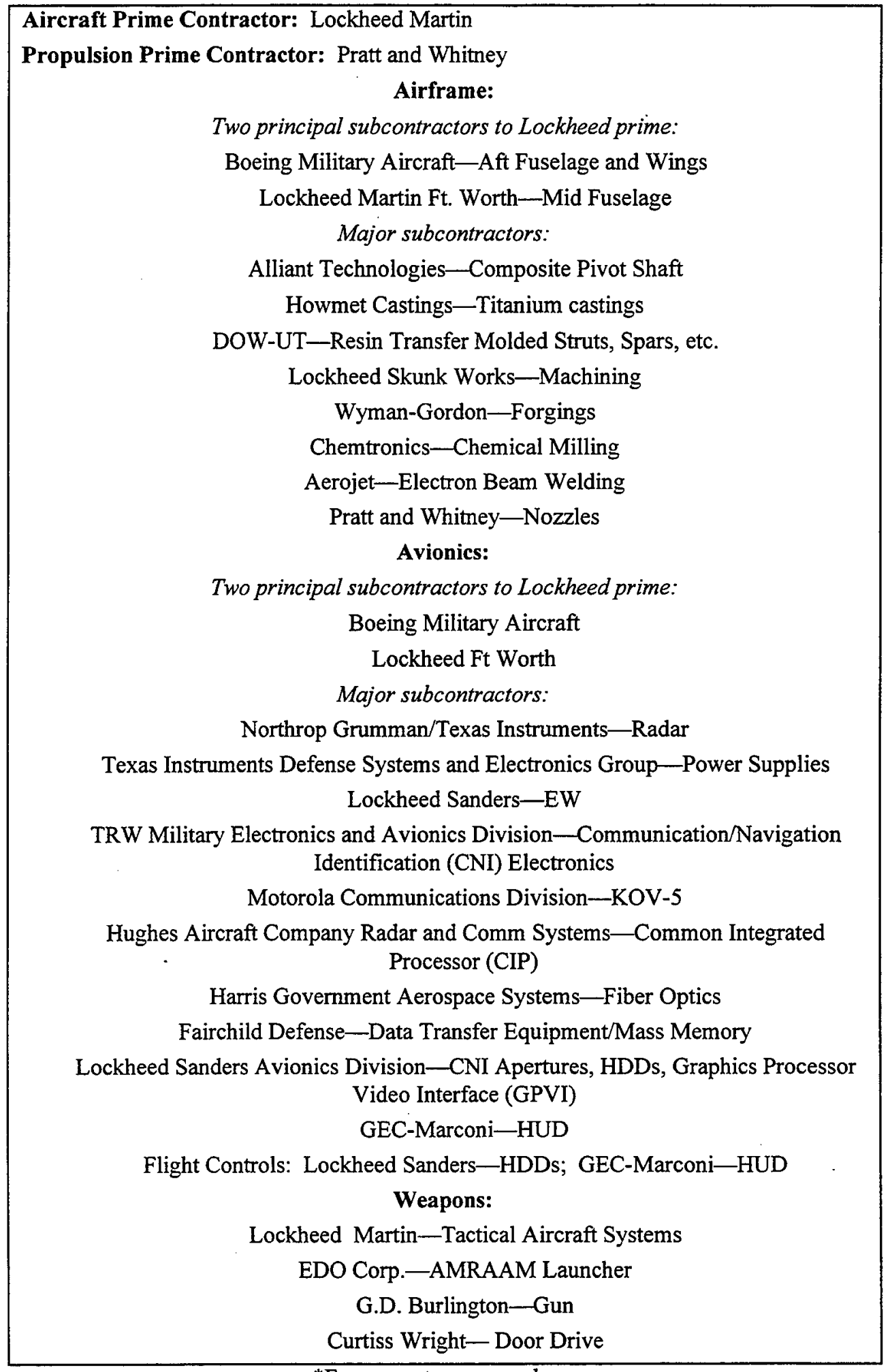

${ }^{*}$ For current program phase 
Table 13. Joint Strike Fighter (JSF) Major Contracts

\begin{tabular}{|cc}
\hline Concept Development Phase (CDP) & Boeing \\
& Lockheed Martin \\
& Pratt \& Whitney
\end{tabular}

Ground and flight demonstrations and continued concept refinement for a tri-Service family of aircraft that meets the Services' needs and optimizes commonality among the variants to minimize life cycle costs; supporting propulsion efforts.

\title{
Technology Maturation Contracts*
}

Effort

Advanced Lightweight Aircraft Fuselage Structure

(ALAFS)

\section{Contractor McDonnell Douglas}

Demonstrate unitized design and manufacturing methodologies for full scale system application.

JSF Integrated Subsystem Technology (JIST)

\author{
Lockheed Martin \\ McDonnell Douglas \\ Boeing
}

Demonstrate system-level integration of subsystem/electric aircraft concepts that substantially reduce cost.

Simulation Assessment Validation Environments

Lockheed Martin

(SAVE)

Integrate, mature, and demonstrate a set of computer-based modeling and simulation tools to support JSF $E \& M D$.
JSF Manufacturing Demonstrations (JMD)
Hughes
Demonstrate the best "advanced practice" of integrating cost \& design data to support IPP, leading to dramatically reduced product realization/manufacturing costs for JSF.
Integrated Core Processing (ICP)
Boeing
Lockheed Martin
Define affordable open architecture standards to meet a range of requirements. Demonstrate affordable digital processing utilizing an open system architecture.

Multi-Function Integrated Radar Frequency System (MIRFS)

Hughes Northrop/Grumman (former Westinghouse)

Demonstrate a light weight, low cost multi-function array (MFA) which supports radar, ESM, and CNI functions.

$$
\text { Integrated Sensor System (ISS) }
$$

\section{Lockheed Martin McDonnell Douglas}

Leverage $S \& T$ program demonstrating an integrated $R F$ support electronics suite that greatly reduces the cost of radar, EW, and CNI functions.

*Unclassified contracts awarded to date. 


\section{APPENDIX F. SOME CHANGING DOD ACQUISITION PRACTICES}

\section{Selecting Suppliers}

Former practice: DoD program managers did not typically direct firm's program "make or buy" decisions but they did have insight and access to subcontractors by reviewing proposed and actual "make or buy" plans. Without selecting suppliers, the Department of Defense also indirectly influenced supplier selection by imposing detailed "how to" specifications, a practice the Department is dramatically changing in preference for performance specifications. (The Department also elected to manage some supplier products as GFE, discussed in "Packaging New System Buys," below.)

- FARs allow the Department of Defense to review prime's proposed subcontractors and "make or buy" decisions on most kinds of contracts. DoD may reserve the right to agree on a contractor's "make or buy" program if needed to ensure (a) negotiation of reasonable contract prices, (b) satisfactory performance, and (c) implementation of socioeconomic policies. ${ }^{61}$

- For cost-type R\&D work, the DoD contracting officer typically requires the prime to allow DoD review of proposed subcontracting of significant $R \& D$ work.

- Contracting officers have also traditionally required review of a firm's "make or buy" program where they think appropriate, such as on major weapon systems where "make or buy" decisions involve major cost or risk.

- Firms" "make or buy plans" have traditionally been incorporated into their contract with the Department of Defense. Firms are then required to report "make or buy" changes as the contract progresses. ${ }^{62}$ For example, the F-22 EMD contract requires that Lockheed have Air Force approval for certain "make or buy" decisions.

U.S. General Services Administration, FAR, op. cit. Three parts of the FAR have most direct bearing on a contractor's "make or buy" decisions: FAR Subpart 15.7, Make-or-Buy Programs; FAR Part 35.009, Research and Development Subcontracting; and FAR Part 44, Subcontracting Policies and Procedures. The Defense FAR Supplement (DFARS) Subpart 244 also provides subcontracting policy. Note: Per FAR, the Defense Contract Management Command (DCMC) reviews and approves the Department's prime contractors' purchasing policies on a company (not individual program) basis, but this process is not intended to evaluate individual program "make or buy" decisions. DCMC examines a contractor's purchasing policies and procedures and samples individual contract data.

Ibid. 
Today's trend: To streamline paper and management, new programs are increasingly deciding not to review prime contractors' make or buy plans. Review of a sampling of programs showed that many new programs are asking firms to identify major or critical subcontractors before contract award of development phase programs. However, they are deciding not to require a FAR-specified "make or buy" plan to be put on contract. This means that firms will not report "make or buy" details, or be required to update the Department if they change make or buy decisions later.

\section{Packaging New DoD System Buys}

\section{Defining Systems Acquisition Boundaries}

Former practice: The Department of Defense often splits parts of a system purchase along lines that matched requirements, firms' capabilities, or Service mission and organizational boundaries. For example, the Army bought the JSTARS ground stations and the Air Force bought the JSTARS aircraft. Likewise, the Department divided the MILSTAR satellite and ground station procurements between two buying activities.

Today's trend: The Department of Defense is packaging systems, including different mission elements (for example, air and ground) in more integrated solicitations. This helps to remove the Department more clearly from a "systems integrator" role. If the Department solicits space and ground products together, the former "ground" primes become a "make or buy" decision for the new "whole package" prime provider, as space-related capabilities will be paramount in determining the prime. With extremely constrained budgets, there is also a trend towards joint programs, such as the Joint Air-to-Surface Standoff Missile and Joint Strike Fighter. Formerly, these might have been separate Air Force and Navy programs, with potentially separate primes and suppliers.

\section{Defining Life Cycle Acquisition Boundaries}

Former practice: The Department of Defense bought logistics support from a mix of internal DoD and contractor sources. Once weapon production was well underway, the Department tended to internally manage and repair many items, and to contract directly for spare parts and services from suppliers.

Today's trend: There is a trend towards awarding logistics support as a package back to a contractor. In many cases, this may be the weapon system "prime" who may have bid on the logistics support as part of a procurement or support contract option for some period of years. 
For example, a good share of the B-2 program's logistics support will be managed by the prime contractor for life. 63

\section{Defining Government-Furnished Equipment (GFE)}

Former Practice: The Department of Defense elected to manage some subtier products directly and provide them as GFE to the prime contractor. Reasons for a GFE approach include:

- A product area was "exceptional"-risky or critical-requiring more DoD funding focus and monitoring, and the Department wanted an unbiased selection between competing solutions. The F-16 aircraft jet engines and radar were developed and procured on contracts separate from the prime aircraft contract. Awarding separate contracts meant additional Air Force oversight personnel, but it also allowed more product knowledge.

- An important product area was not part of the prime firm's capabilities. The Department of Defense may have competed and procured a subsystem directly if it required very different skills than the prime offered, particularly if the subsystem needed more development. Examples of separately managed GFE products abound in shipbuilding, tracked combat vehicles, and aircraft engines (see Table Fourteen, M1 Abrams Tank GFE). Historically, the Navy provided detailed contract specifications for ships, resulting in a more direct relationship to systems below the prime "shipbuilder."

- In some areas, the Department may have initially procured the product through the prime, but subsequently it decided to "break out" the product to buy directly from the source. DoD procurement policy requires all programs to examine the possibility of component breakout if it might offer cost sävings to the Department. 64

\footnotetext{
63 "Life cycle" logistics support contracts are usually renegotiated every three to five years, even if the contractor remains the same.

64 Appendix D, "Component Breakout," Defense FAR Supplement (DFARS), http://www.dtic.mil/dfars/
} 


\section{Decreased DoD manning}

Former practice: Program offices had a much larger staff and a constant presence at contractors' facilities. On the F-16 program, for example, the Air Force routinely held periodic reviews of nearly all major first-tier subcontractors (Pratt and Whitney, Westinghouse, Singer-Kearfott, etc.).

Today's trend: Program offices are managing with leaner staffs and by teaming with contractors. They have decreased their review of daily activities, but they also have decreased their knowledge of suppliers. DoD contract administration personnel (located at contractors' plants) have been reduced by over $40 \%$ since 1990 . They also increasingly manage priority areas and stand back from suppliers below prime.

- On the F-22, for example, the program office uses standing integrated product teams (IPTs) with the prime contractor to manage important program areas. Subtier suppliers, at the first level below the prime, would typically become involved in the IPTs only if there were a particular issue or problems. Suppliers at the second level or below the prime would rarely interact with the Air Force. 
